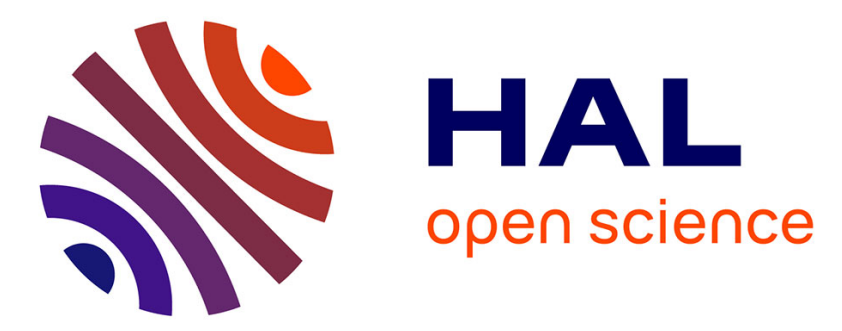

\title{
Radiogenic and stable Ce isotope measurements by 1 thermal ionisation mass spectrometry
}

P. Bonnand, C. Israel, Maud Boyet, R. Doucelance, Delphine Auclair

\section{To cite this version:}

P. Bonnand, C. Israel, Maud Boyet, R. Doucelance, Delphine Auclair. Radiogenic and stable Ce isotope measurements by 1 thermal ionisation mass spectrometry. Journal of Analytical Atomic Spectrometry, 2019, 34 (3), pp.504-516. 10.1039/c8ja00362a . hal-02110895

\section{HAL Id: hal-02110895 \\ https://hal.uca.fr/hal-02110895}

Submitted on 25 Apr 2019

HAL is a multi-disciplinary open access archive for the deposit and dissemination of scientific research documents, whether they are published or not. The documents may come from teaching and research institutions in France or abroad, or from public or private research centers.
L'archive ouverte pluridisciplinaire HAL, est destinée au dépôt et à la diffusion de documents scientifiques de niveau recherche, publiés ou non, émanant des établissements d'enseignement et de recherche français ou étrangers, des laboratoires publics ou privés. 
P. Bonnand ${ }^{1 *}$, C. Israel $l^{1}$, M. Boyet ${ }^{1}$, R. Doucelance ${ }^{1}$, D. Auclair $^{1}$

5

6

7

8

9

10

11

12

13

14

15

16

17

18

19

20

$21{ }^{*}$ Corresponding author

22 Email address: pierre.bonnand@uca.fr

23

24

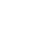

6

7

9 F-63000 Clermont-Ferrand, France.

10

11

12

13

14

15

16

17

18

23 Tel. No: +33 (0)473346783

\section{Radiogenic and stable Ce isotope measurements by thermal ionisation mass spectrometry}

81 Université Clermont Auvergne, CNRS, IRD, OPGC, Laboratoire Magmas et Volcans, 
Techniques for the separation of Cerium (Ce) from silicate matrices and for the analysis of radiogenic $\left(\varepsilon^{138} \mathrm{Ce}\right)$ and mass dependent $\left(\delta^{142} \mathrm{Ce}\right)$ Ce isotope variations by Thermal Ionisation Mass Spectrometer (TIMS) are presented in this study. We developed a static acquisition method associated with $10^{13} \Omega$ amplifiers that allows (i) the precise determination of the ${ }^{140} \mathrm{Ce}$ peak tailing effect on the lighter $\mathrm{Ce}$ isotopes, and (ii) the reduction of the counting time necessary to obtain high precision isotopic composition. The long-term reproducibility obtained for our Ce reference material (Ce-LMV) on the ${ }^{138} \mathrm{Ce} /{ }^{142} \mathrm{Ce}$ ratio is $0.02257053 \pm 0.00000061$ (27 ppm, 2 s.d., $\mathrm{n}=48$ ). The new Ce-LMV has been calibrated against the commonly used AMES reference material $(0.02257426 \pm 0.00000068$ (30 ppm, 2 s.d., $n=25$ ). The static cup configuration also allows a more stable determination of the tailing effect from the ${ }^{140} \mathrm{Ce}$ isotope peak onto ${ }^{136} \mathrm{Ce}$ and ${ }^{138} \mathrm{Ce}$. Finally, the $10^{13} \Omega$ amplifiers permit a better determination of the tailing effect during low voltages measurements. A new method to measure mass dependent Ce isotope variations based on the double spike method has also been developed. Uncertainty propagation calculations demonstrate that the best spike mixture is a ${ }^{136} \mathrm{Ce}^{138} \mathrm{Ce}^{140} \mathrm{Ce}$ triple spike. We have calibrated an in-house triple spike used to correct for instrumental mass bias effect and fractionation of Ce isotopes during Ce separation. Numerical simulations demonstrate the effect of potential isobaric interferences from $\mathrm{Ba}, \mathrm{Nd}$ and La and highlight the need for an efficient chemical separation. Two loading techniques were tested for triple spike measurements (oxide and metal). The best reproducibility for $\delta^{142} \mathrm{Ce}$ is obtained for the metal runs and is about $\pm 0.028 \%$. Although this technique has been developed for silicate matrices, the mass spectrometry method can be applied to other matrices such as carbonates. The newly calibrated Ce reference material is available to the community upon request. 


\section{Introduction}

The Rare Earth Elements (REE) are a group of 17 elements (Lanthanides (La to Lu) as well as Scandium and Yttrium), widely used in the geosciences community because of their similar behaviour in natural systems. REE can be found as minor or trace elements in most natural environments and are sometimes more concentrated in some minerals (e.g. monazite) or $\mathrm{CeO}_{2}$ nanoparticles. The main characteristic of the REE group is that their oxidation state in most natural system is $\mathrm{REE}^{3+}$ except for Ce and Eu. Europium can form Eu(II) ions in reduced conditions and $\mathrm{Ce}$ is more stable in $\mathrm{Ce}(\mathrm{IV})$ in oxidised conditions. The differences in chemical behaviour between Ce and Eu compared with the rest of the REE have been extensively used in the literature via the positive and negative anomalies. For example, seawater is characterised by a large negative Ce anomaly due to the insolubility of Ce(IV) relative to other $\operatorname{REE}(I I I) .{ }^{1}$ In this case, $\mathrm{Ce}$ is oxidised to $\mathrm{Ce}(\mathrm{IV})$ and is removed from seawater leaving the residue Ce depleted and therefore creating a negative Ce anomaly. Cerium anomalies have also been used in high temperature settings such as zircon crystallisation. $\cdot^{2-5}$ Indeed, the amplitude of the Ce anomaly in zircon is directly proportional to the redox conditions and can potentially be used as an oxybarometer. ${ }^{2,3}$ Cerium is a lithophile element and behaves incompatibly in magmatic systems, meaning that upon melting and/or crystallisation Ce remains in the melt.

Cerium has four stable isotopes, ${ }^{136} \mathrm{Ce},{ }^{138} \mathrm{Ce},{ }^{140} \mathrm{Ce}$ and ${ }^{142} \mathrm{Ce}$ with relative abundance of $0.185 \%$, $0.251 \%, 88.45 \%$ and $11.114 \%$, respectively (Fig. 1$)^{6}$. Cerium isotopes vary in relative abundance by two orders of magnitude, which makes analyses more challenging than, for example, $\mathrm{Nd}$, which only vary by a factor of five. Indeed, ${ }^{138} \mathrm{Ce}$ and ${ }^{136} \mathrm{Ce}$ are about 400 times less abundant than the main $\mathrm{Ce}$ isotope $\left({ }^{140} \mathrm{Ce}\right)$. The small Ce isotopic variations observed in natural systems mean that high precision measurements are required. Furthermore, ${ }^{138} \mathrm{Ce}$ is affected by isobaric interferences from ${ }^{138} \mathrm{Ba}$, which is the most abundant Ba isotope, and from ${ }^{138} \mathrm{La}$, which is the least abundant La isotope. There is also an isobaric interference from ${ }^{142} \mathrm{Nd}$ onto ${ }^{142} \mathrm{Ce}$. Additionally, ${ }^{136} \mathrm{Ce}$ and ${ }^{138} \mathrm{Ce}$ are affected during measurement on a TIMS by tailing effect from mass ${ }^{140} \mathrm{Ce} .{ }^{7}$ The measurement of $\mathrm{Ce}$ isotopes at high 
precision is thus challenging. This requires both a good chemical separation between Ce and the isobaric interference elements (mainly $\mathrm{Ba}$ and $\mathrm{Nd}$ ) and a specific analytical setting.

Cerium isotopes have been previously studied for the radiogenic variations of ${ }^{138} \mathrm{Ce} .{ }^{8-14} \mathrm{The}$ La-Ce systematic is based on the $\beta$-decay of ${ }^{138}$ La to stable ${ }^{138} \mathrm{Ce}$. The low abundance of ${ }^{138} \mathrm{La}$ and its long half-life $\left(\beta\right.$-decay; $\mathrm{t}^{1 / 2}=292.5 \times 10^{9}$ years, 14$)$ means that the observed variations in ${ }^{138} \mathrm{Ce} /{ }^{142} \mathrm{Ce}$ are small ( $~ 80-120 \mathrm{ppm})$ compared to variations in the Sm-Nd systematic ( 600 ppm). ${ }^{16}$ Nevertheless, the La-Ce system has been successfully applied as a geochemical tracer together with other isotopic systems (Rb-Sr, Sm-Nd, Lu-Hf, Re-Os and U-Th-Pb) and for the age determination of rocks. ${ }^{17-21}$ It has also been successfully used for terrestrial and lunar basalts, manganese nodules and seawater. ${ }^{22-26}$ The Ce isotopes variations can be reported in different notations. ${ }^{12}$ In this study, we choose to report the variations in three notations:

$$
{ }^{138} \mathrm{Ce} /{ }^{142} \mathrm{Ce} \text { sample }
$$

which is the tail, oxide and mass fractionated corrected ratio (see text below for details).

$$
{ }^{138} \mathrm{Ce} /{ }^{136} \mathrm{Ce}=\frac{{ }^{138} \mathrm{Ce} /{ }^{142} \mathrm{Ce}}{{ }^{136} \mathrm{Ce} /{ }^{142} \mathrm{Ce} \text { natural }}
$$

where the ratio ${ }^{136} \mathrm{Ce} /{ }^{142} \mathrm{Ce}_{\text {natural }}$ is fixed to $0.01688 .{ }^{23}$

$$
\varepsilon{ }^{138} \mathrm{Ce}=\left(\frac{{ }^{138} \mathrm{Ce} /{ }^{142} \mathrm{Ce}}{{ }^{138} \mathrm{Ce} e /{ }^{142} \mathrm{C} e_{L M V}}-1\right) * 10000
$$

where ${ }^{138} \mathrm{Ce} /{ }^{142} \mathrm{Ce}$ Lmv is the ratio obtained for our Ames Ce reference material (Ce-LMV).

Mass dependent Ce isotopic variations have also been recently explored. ${ }^{27}$ Due to the chemical behaviour of Ce described above, it has been suggested that Ce isotopes could be used as a redox proxy. ${ }^{28}$ Mass dependent Ce isotope measurements have been performed for natural Fe-oxides and absorption experiments. ${ }^{29}$ The results suggest that Ce isotopes are fractionated during absorption 
onto Fe-oxyhydroxides and that isotopic fractionation occurring in natural systems could be linked to redox reactions. More recently, $\mathrm{CeO}_{2}$ nanoparticles have also been analysed in order to characterise their impact on natural systems. ${ }^{30}$ Several studies have presented analytical techniques to separate and analyse mass dependent $\mathrm{Ce}$ isotope variations..$^{27,30}$ In these studies, mass dependent $\mathrm{Ce}$ isotope variations have been analysed with Multi-Collector Inductively Coupled Plasma Mass spectrometers (MC-ICPMS) using the external doping technique with either $\mathrm{Sm}^{26}$ or $\mathrm{Ba}^{30}$ The Ce isotopic composition is reported as the per mil variation from the Ce isotope reference material LMV using the equation:

$$
\delta^{142} \mathrm{Ce}=\left(\frac{{ }^{142} \mathrm{Ce} /{ }^{140} \mathrm{Ce}}{{ }_{\text {sample }}}-1\right) * 1000
$$

In this study, we propose a new methodology to measure radiogenic variations of $\mathrm{Ce}$ isotopes. We developed a new static cup configuration on a Thermal Ionisation Mass Spectrometer (TIMS) that allows the simultaneous measurement of $\mathrm{Ce}$ isotopes (and its isobaric interference elements) together with four masses used to define the tailing from ${ }^{140} \mathrm{Ce}$ onto ${ }^{136} \mathrm{Ce}$ and ${ }^{138} \mathrm{Ce}$. In comparison to previous techniques that used a multi-static acquisition method ( 2 to 6 lines), this new method allows the reduction of the length of high precision measurements. We also present a new triple spike $\left({ }^{136} \mathrm{Ce}-\right.$ ${ }^{138} \mathrm{Ce}-{ }^{140} \mathrm{Ce}$ ) method to measure mass dependent $\mathrm{Ce}$ isotope variations with a better precision than previous analytical methodologies.

\section{Analytical techniques}

\subsection{Chemical separation}

Reference materials and samples were prepared in the clean laboratory in class 100 laminar flow hoods at the Laboratoire Magmas et Volcans (Clermont Ferrand). All acids ( $\mathrm{HCl}, \mathrm{HNO}_{3}$ and $\mathrm{HF}$ ) were distilled in the Savillex ${ }^{\circledR}$ acid still DST-1000. PFA Savillex ${ }^{\circledast}$ beakers were cleaned with concentrated $\mathrm{HNO}_{3}$ and $\mathrm{HCl}$ on the hotplate at $115 \stackrel{\circ}{\circ} \mathrm{C}$ and then rinsed in ultrapure $\mathrm{H}_{2} \mathrm{O}$. Our high purity Ce metal reference material was bought from AMES Laboratory and will be thereafter called Ce-LMV. M. Willbold provided the second reference material analysed in this study (Ce-AMES; 6). The Ce reference 
material (Ce-LMV) was dissolved in $\mathrm{HCl}$ on the hotplate for 48 hours. Approximately $50 \mathrm{mg}$ of whole rock basalts reference materials (BHVO-2 and $\mathrm{BCR}-2$ ) were dissolved using concentrated $\mathrm{HNO}_{3}-\mathrm{HF}-\mathrm{HCl}$ acid mixtures. The fully dissolved sample was evaporated to dryness and then re-dissolved in $2.5 \mathrm{M}$ $\mathrm{HCl}$ for chemical separation.

The chemical separation method used in this study is modified after Tazoe et al. $(2007)^{31}$, Li et al. $(2015)^{32}$ and Bellot et al. $(2015)^{20}$. Only a brief description is given here. The chemical separation developed to separate the Ce fraction to silicate matrices involved three columns. The first step was used to separate the REEs from the main cations of the matrix (Fig. 2). In order to achieve this separation, the samples were loaded in $2.5 \mathrm{~N} \mathrm{HCl}$ onto $1 \mathrm{~mL}$ of $A G 50 \times 8,200-400$ mesh resin in BioRad $10 \mathrm{ml}$ column. Prior to the chemistry, the resin was cleaned with $10 \mathrm{ml} 6 \mathrm{M} \mathrm{HCl}$. The REE stuck to the resin while the main cations were eluted from the resin. Ba was then eluted in $2 \mathrm{M} \mathrm{HNO}_{3}$ and the REE were finally eluted in $6 \mathrm{M} \mathrm{HCl}$ (Fig. 2a). The second column procedure was designed to separate $\mathrm{Ce}^{4+}$ from the other REE using LnSpec Eichrom resin $(50-100 \mu \mathrm{m})$ in $2 \mathrm{ml} \mathrm{Bio-Rad} \mathrm{columns.}{ }^{31}$ The oxidation of $\mathrm{Ce}$ from $\mathrm{Ce}^{3+}$ to $\mathrm{Ce}^{4+}$ was achieved with $0.5 \mathrm{ml}$ of $\mathrm{NaBrO}_{3}(20 \mathrm{mM})$ in $10 \mathrm{M} \mathrm{HNO}_{3}$. Prior to the chemistry, the resin was cleaned with $5 \mathrm{ml} 6 \mathrm{M} \mathrm{HCl}$. The samples were loaded onto $0.1 \mathrm{~mL} \mathrm{LnSpec}$ Eichrom resin in $10 \mathrm{M} \mathrm{HNO}_{3}+\mathrm{NaBrO}_{3}$ and $\mathrm{Ce}^{4+}$ stuck to the resin while the remaining $\mathrm{REE}^{3+}$ were eluted in the loading solution (Fig. 2b). The Ce fraction was eluted in $6 \mathrm{M} \mathrm{HCl}+\mathrm{H}_{2} \mathrm{O}_{2}$. Finally, the samples were then processed through the first step of the chemistry to make sure the Ce fraction was cleaned of any remaining matrix cations.

\subsection{Mass spectrometry}

Isotopic measurements were performed on a ThermoScientific Thermal Ionisation Mass spectrometer Triton Plus (TIMS) at the Laboratoire Magmas et Volcans. The Ce reference materials were analysed in both oxide and metal forms using the double filament technique. For the oxides analyses, the Ce fraction was loaded in $\mathrm{HCl}$ onto outgassed Re filament together with $0.5 \mu \mathrm{L}$ of $1 \mathrm{M}$ $\mathrm{H}_{3} \mathrm{PO}_{4}$. For the metal runs, the Ce fraction was loaded in $\mathrm{HCl}$ onto outgassed C-doped zone refined $\mathrm{Re}$ 
filaments. Aquadag was added to outgassed Re filament and the filament was then re-degassed. The carbon acted as a reducer and stopped the emission and ionisation of Ce oxides. During a typical $\mathrm{Ce}$ metal measurement the $\mathrm{CeO} / \mathrm{Ce}$ ratio was always lower than 0.002 .

During the course of this study, several cup configurations have been tested (Table 1). Firstly, the Ce-AMES reference material was analysed using the dynamic method previously proposed to measure Ce isotopes. ${ }^{7,20}$ This cup configuration requires a multi-static acquisition method. The first line is for measuring $\mathrm{Ce}, \mathrm{Nd}$, La and Ba masses with ${ }^{139} \mathrm{La}^{16} \mathrm{O}$ in the central cup (Table 1). The tailing is measured on the second line after a -0.5 mass unit (MU) jump. In this configuration, both elemental and tailing signals are measured using $10^{11} \Omega$ resistors. For this study, we have established a new cup configuration where mass and half-mass signals are measured simultaneously. In this case, the acquisition is achieved in a static mode and different resistors can be used for both signals and tailing masses. This technique has two main advantages. First, the tailing effect on mass ${ }^{136} \mathrm{Ce}$ and ${ }^{138} \mathrm{Ce}$ can be estimated more precisely. Second, the static acquisition method reduces the duration of our isotopic measurements by a third.

The oxide runs were performed in two main cup settings (Table 1). In the first setting (cup configurations \#2 and 3), ${ }^{140} \mathrm{Ce}^{16} \mathrm{O}$ was not measured and the signal was adjusted to have $10 \mathrm{~V}(0.1 \mathrm{nA})$ of ${ }^{142} \mathrm{Ce}{ }^{16} \mathrm{O}$. In the second setting (cup configuration \#4, 5 and 6 ), ${ }^{140} \mathrm{Ce}{ }^{16} \mathrm{O}$ was measured in $\mathrm{H} 2$. The difference between cup configurations in each setting is the amplifier combination (Table 1). The cup configuration \#7 was designed to measure all Ce isotopes and isobaric interferences together with tailing masses. Due to the increased amount of ${ }^{136} \mathrm{Ce}$ and ${ }^{138} \mathrm{Ce}$ after spike addition, the $10^{11} \Omega$ and $10^{13}$ $\Omega$ amplifiers were used for all elemental signals and tailing masses, respectively. The cup configuration \#8 was designed to measure $\mathrm{Ce}$ and its isobaric interference isotopes in metal form. In this setting, all cups were associated with $10^{11} \Omega$ amplifiers and no tailing masses were monitored. Typical runs on the mass spectrometer consist of 27 blocks of 20 cycles with 8.462 seconds integration time. Each block started with a baseline measurement of 30 seconds. The gain calibrations for the $10^{10}, 10^{11}$ and 
V). The gain calibrations for the $10^{13} \Omega$ resistors were performed weekly (when used) with $\mathrm{Nd}$ signals following the ThermoScientific procedure.

\subsection{The triple spike technique}

The use of an isotopically enriched solution ("double spike") to correct for fractionation of stable isotopes during sample processing and for instrumental mass bias effects has long been recognised as a powerful tool..$^{33-35}$ This methodology has now been successfully applied to many isotopes systems including $\mathrm{Fe}, \mathrm{Sr}, \mathrm{Zn}, \mathrm{Cd}$ and $\mathrm{Cr}^{36-39}$ For $\mathrm{Ce}$, the double spike technique is applicable to both terrestrial and extra-terrestrial samples because the Ce isotope radiogenic and nucleosynthetic variations are small and will not generate a large influence in the spike deconvolution. Moreover, this technique allows the determination of Ce concentration by isotope dilution.

In this study, we explore the best spike composition to measure mass dependent Ce isotopic variations. Three spikes are commercially available: ${ }^{136} \mathrm{Ce}-{ }^{140} \mathrm{Ce},{ }^{138} \mathrm{Ce}-{ }^{140} \mathrm{Ce}$ and ${ }^{142} \mathrm{Ce}$. The ${ }^{142} \mathrm{Ce}$ spike has already been used for isotope dilution measurement in previous studies. In order to optimise carefully the spike composition, a number of mixtures between commercially available spikes have been investigated (Table 2). This requires: (1) establishing the most appropriate spike composition; (2) solving the double spike equations and (3) adding the appropriate amount of spike to the reference material. The optimisation is described by the uncertainty magnification term, $\gamma$ :

$$
\gamma=\sigma_{\mathrm{DS}} / \sigma_{\mathrm{nat}}
$$
the uncertainty of the natural unspiked run. Our calculations are similar to those described by Galer $(1999)^{40}$ but we deconvolve the runs using the exponential mass fractionation law. The spike compositions used in the calculations are given in Table 2 and the results of the calculations are presented in Figure 3. Three spike mixtures were investigated: ${ }^{136} \mathrm{Ce}-{ }^{140} \mathrm{Ce}-{ }^{142} \mathrm{Ce},{ }^{138} \mathrm{Ce}-{ }^{140} \mathrm{Ce}-{ }^{142} \mathrm{Ce}$ and ${ }^{136} \mathrm{Ce}-{ }^{138} \mathrm{Ce}-{ }^{-140} \mathrm{Ce}$. In Figure 3, the lower uncertainty magnification term is obtained for the ${ }^{136} \mathrm{Ce}-{ }^{138} \mathrm{Ce}-$ 
${ }^{140} \mathrm{Ce}$ triple spike. The best proportion of ${ }^{136} \mathrm{Ce}-{ }^{140} \mathrm{Ce}$ spike in the triple spike mixture is about $50 \%$. In order to calculate the optimal spike/sample ratio, the deconvolution program is run using different proportions of spike and sample. We use an ion model based on the one described by Ludwig $(1986)^{41}$ to calculate the uncertainty on signal intensity of each isotope which is then propagated to calculate the uncertainty on the double spike deconvolution procedure. The uncertainty magnification term is calculated using Monte Carlo simulation in which the uncertainties of the four Ce isotopes signals are used to generate 540 data points for each analysis. These points have a Gaussian distribution around the mean value. The results obtained after the Monte Carlo simulations (540 cycles) are processed through the deconvolution procedure and the uncertainty $\left(\sigma_{D S}\right)$ of the deconvolved data is calculated. For the triple spike ${ }^{136} \mathrm{Ce}-{ }^{138} \mathrm{Ce}-{ }^{-140} \mathrm{Ce}$, the uncertainty magnification term is always less than 4 . Figure $3 \mathrm{~b}$ illustrates the optimal spike/sample ratio for the two double spikes $\left({ }^{136} \mathrm{Ce}-{ }^{140} \mathrm{Ce}\right.$ and $\left.{ }^{138} \mathrm{Ce}-{ }^{140} \mathrm{Ce}\right)$ and the triple spike $\left({ }^{136} \mathrm{Ce}-{ }^{138} \mathrm{Ce}-{ }^{140} \mathrm{Ce}\right)$. It is important to note that the two double spikes can produce low uncertainty magnification terms but the proportion of spike required is high (spike/sample ratio $=0.8)$. The triple spike however has a more flatten uncertainty model curve, which means that not only the uncertainty magnification term is better for almost all mixtures but also that optimal spiking is facilitated. The best spike/sample ratio for the triple spike is 0.33 .

An in-house ${ }^{136} \mathrm{Ce}_{-}{ }^{138} \mathrm{Ce}-{ }^{140} \mathrm{Ce}$ triple spike was prepared from ${ }^{136} \mathrm{Ce}-{ }^{140} \mathrm{Ce}$ and ${ }^{138} \mathrm{Ce}-{ }^{-140} \mathrm{Ce}$ cerium oxides spikes purchased from IsoFlex ${ }^{\circledR}$ and their enrichment factors were $42.5 \%$ and $41.6 \%$, respectively. Two double-spike solutions were made by dissolving the Ce-oxides in $6 \mathrm{M} \mathrm{HCl}-\mathrm{H}_{2} \mathrm{O}_{2}$. The Ce spikes were purchased in oxide form and $\mathrm{H}_{2} \mathrm{O}_{2}$ helped to reduce $\mathrm{Ce}$ and facilitated the dissolution. The triple spike was then prepared by mixing the double spikes in the appropriate proportions. The triple spike was calibrated by TIMS at the Laboratoire Magmas et Volcans using the loading techniques described above. The pure Ce-LMV reference material, the pure triple spike and spike/standard mixtures were analysed. The isotopic composition of the triple spike is then calculated by treating the pure triple spike as an unknown. The composition of the triple spike was derived from 26 separate analyses and is reported in Table 3. 


\section{Data Processing}

The Ce isotopic composition of the samples and reference materials was determined offline but baseline and gain corrections were performed online with the ThermoScientific software. The deconvolution procedures used for unspiked and spiked runs are described in details in the paragraphs below. The deconvolution procedure for both unspiked and spiked runs can be divided in three main steps: tail correction on mass ${ }^{136} \mathrm{Ce}$ and ${ }^{138} \mathrm{Ce}$, oxide corrections and mass bias fractionation corrections.

\subsection{Tail correction}

The large dynamic range in Ce isotopes, with ${ }^{140} \mathrm{Ce}$ accounting for $88.45 \%$ of total $\mathrm{Ce}$, has long been recognised as a problem for obtaining high precision Ce isotope measurements (e.g. 7). Indeed, the small proportion of ${ }^{136} \mathrm{Ce}$ and ${ }^{138} \mathrm{Ce}, 0.19$ and $0.25 \%$ respectively, means that we need to measure high intensity beams (e.g. $80 \mathrm{~V}(0.8 \mathrm{nA})$ for $\left.{ }^{140} \mathrm{Ce}^{16} \mathrm{O}\right)$ in order to obtain accurate and precise Ce isotopic compositions. It has been shown that running at high intensities produces a tailing effect on mass ${ }^{136} \mathrm{Ce}$ and ${ }^{138} \mathrm{Ce}$. Classically, the tailing contribution was calculated with half masses analysis (e.g. 7) in a dynamic sequence (cup configuration \#1, Table 1). In this contribution, we developed a simultaneous measurement of the $\mathrm{Ce}$ isotopes and of the tailing contribution. Two cups were intercalated between masses 152 and 154 and one cup between 154 and 156 (see Table 1, Fig. 4). This new cup configuration allows the measurement of intensities generated by the large ${ }^{140} \mathrm{Ce}$ beam on mass 156.5 and 154.6. The intercalated cup positions were determined by measuring the distance between the cups on large mass scans using a stable Ce beam. This step is critical in order to perform an accurate tail correction. In order to determine the contribution of the tailing on mass ${ }^{136} \mathrm{Ce}$ and ${ }^{138} \mathrm{Ce}$, we fitted an exponential equation through the measured masses. The increased integration time (from $4 \mathrm{~s}$ to $8 \mathrm{~s}$ ) compared to our dynamic measurements means that the tailing contribution can be assessed more precisely. Furthermore, the static run suppresses the need for magnet shift and allows a more stable measurement. The uncertainty induced by small offset in magnet position described in details in Willig 
and Stracke $(2017)^{13}$ can therefore be avoided. The static cup configuration allows a more stable determination of the tail effect ( 0.6 to $0.9 \varepsilon$ unit) compared to previous studies ( 0.0 to $1.6 \varepsilon$ unit ${ }^{42}$ and 0.15 to $1.8 \varepsilon$ unit $\left.{ }^{13}\right)$. All ${ }^{136} \mathrm{Ce}$ and ${ }^{138} \mathrm{Ce}$ signals mentioned hereafter in the manuscript are tail corrected (unless noted otherwise).

\subsection{Oxide correction and mass bias correction}

During the measurement of $\mathrm{Ce}$ isotopes in oxide form, the measured raw signals are the sums of the isotopes of interest and an oxide interference following the equation:

$$
{ }^{\mathrm{X}} \mathrm{Ce}^{16} \mathrm{O}=\mathrm{I}^{(\mathrm{X}+16)}-{ }^{(\mathrm{X}-2)} \mathrm{Ce}^{18} \mathrm{O}
$$

256

257

where $X$ can be 138,140 and 142 and $I^{(X+16)}$ is the measured intensities on the mass $X+16$ corresponding to the three oxide masses. With $\mathrm{R}={ }^{18} \mathrm{O} /{ }^{16} \mathrm{O}$, equation 6 can be easily expressed as:

$$
{ }^{\mathrm{X}} \mathrm{Ce}^{16} \mathrm{O}=\mathrm{I}^{(\mathrm{X}+16)}-{ }^{(\mathrm{X}-2)} \mathrm{Ce}^{16} \mathrm{O} * \mathrm{R}
$$

The oxide correction methodology used in this study follows a similar protocol to that of Willig and Stracke $(2017)^{13}$ although it is adapted for the triple spike deconvolution procedure.

For the unspiked runs, an iterative process was followed whereby the ratio $\mathrm{R}$ is assumed to be 0.00213 and signals measured on masses 154,156 and 158 are corrected for the contribution of ${ }^{136} \mathrm{Ce}^{18} \mathrm{O},{ }^{138} \mathrm{Ce}{ }^{18} \mathrm{O}$ and ${ }^{140} \mathrm{Ce}{ }^{18} \mathrm{O}$ respectively following equation 7 . The ${ }^{138} \mathrm{Ce} /{ }^{142} \mathrm{Ce}$ and ${ }^{140} \mathrm{Ce} /{ }^{142} \mathrm{Ce}$ ratios (when measured) were corrected for mass bias fractionation using the exponential law and the ${ }^{136} \mathrm{Ce} /{ }^{142} \mathrm{Ce}$ ratio of $0.01688 .{ }^{43-45}$ Using the obtained Ce isotopes intensities the fractionation factor $(\beta)$ is then determined using the exponential mass fractionation law:

$$
\beta=\frac{\ln \left(\frac{{ }^{136} \mathrm{Ce} /{ }^{142} \mathrm{Ce} \text { true }}{{ }^{136} \mathrm{Ce} /{ }^{142} \mathrm{Ce} \text { measured }}\right)}{\ln \left(\frac{M^{136} \mathrm{Ce} e^{16} \mathrm{O}}{M^{142} \mathrm{Ce} e^{16} \mathrm{O}}\right)}
$$


where ${ }^{136} \mathrm{Ce} /{ }^{142} \mathrm{Ce}_{\text {measured }}$ is the tail and oxide corrected ${ }^{136} \mathrm{Ce}^{16} \mathrm{O} /{ }^{142} \mathrm{Ce}^{16} \mathrm{O}$ measured ratio and ${ }^{136} \mathrm{Ce} /{ }^{142} \mathrm{Ce}$ true is fixed to $0.01688 . \mathrm{M}^{136} \mathrm{Ce}^{16} \mathrm{O}$ and $\mathrm{M}^{142} \mathrm{Ce}^{16} \mathrm{O}$ are the atomic masses of ${ }^{136} \mathrm{Ce}^{16} \mathrm{O}$ and ${ }^{142} \mathrm{Ce}^{16} \mathrm{O}$, respectively. Using the fractionation factor calculated above, a new $\mathrm{R}$ value can be calculated using the equation:

$$
R=\frac{{ }_{{ }^{136} C e^{16} O} e^{18} O_{\text {measured }}}{{ }^{136} C e} *\left(\frac{M^{136} C e^{16} O}{M^{142} C e^{18} O}\right)^{\beta}
$$

where ${ }^{136} \mathrm{Ce}^{16} \mathrm{O} /{ }^{142} \mathrm{Ce}^{18} \mathrm{O}_{\text {measured }}$ is the measured ratio. The new $\mathrm{R}$ value is then used to calculate new oxide contributions on masses 152,154 and 156 . This iterative deconvolution is conducted until the $\mathrm{R}$ value reaches a plateau which is usually obtained after three iterations. The $\beta$ value obtained on the last iterative step is used to calculate the corrected Ce isotopic composition. When ${ }^{140} \mathrm{Ce}^{16} \mathrm{O}$ is not measured, a fixed value for the ${ }^{140} \mathrm{Ce} /{ }^{142} \mathrm{Ce}$ ratio is used to correct the contribution of ${ }^{140} \mathrm{Ce}^{18} \mathrm{O}$ on ${ }^{142} \mathrm{Ce}{ }^{16} \mathrm{O}$ signals.

For the triple spiked analysis, we follow the same principle except that mass bias fractionation is solved following the equation 10 :

$$
F^{i}\left(P_{s p}^{r e f}, f_{\text {nat }}, f_{\text {mix }}\right)=P_{s p}^{r e f} r_{s p}^{i}+\left(1-P_{s p}^{r e f}\right) r_{\text {nat }}^{i}\left(\frac{M^{i}}{M^{r e f}}\right)^{f_{\text {nat }}}-r_{\text {mix }}^{i}\left(\frac{M^{i}}{M^{r e f}}\right)^{f_{m i x}}=0
$$

where $r_{\text {sp }}^{i}$ is the isotope ratio of $i$ in the spike, $r_{\text {nat }}^{i}$ and $r_{\text {mix }}^{i}$ are the measured isotope ratios of $i$ in the sample and mixture, and $\mathrm{M}_{\mathrm{i}}$ and $\mathrm{M}_{\text {ref }}$ are the true masses of the isotope oxides $(i+16)$. The $\mathrm{F}^{\mathrm{i}}$ function is a closure function for the spike sample mixture, which must be equal to zero. The equation is solved using an iterative Newton-Raphson procedure that recovers the proportion of spike in the mixture $\left(\mathrm{Pref}_{\mathrm{sp}}\right)$, the fractionation factor for the spike-sample mixture $\left(\mathrm{f}_{\text {mix }}\right)$ and finally the fractionation factor for the sample $\left(f_{\text {nat }}\right)$. Using the measured ${ }^{136} \mathrm{Ce}^{16} \mathrm{O} /{ }^{142} \mathrm{Ce}{ }^{18} \mathrm{O}$ ratio and the mixture fractionation factor $\left(f_{\text {mix }}\right)$, we calculated a new $R$ value which is then used to correct for oxide interferences. The deconvolution procedure finishes when $\mathrm{R}$ value does not change, within $5 \mathrm{ppm}$, from one iteration 
step to the other. We then obtain our final $f_{\text {nat }}$ value that is used to calculate the isotopic composition of the original sample. The isotope ratios for the Ce-LMV reference material used for referencing our isotope data (to calculate $\delta^{142} \mathrm{Ce}$ ) in this study were obtained by TIMS by internal normalisation to ${ }^{136} \mathrm{Ce} /{ }^{142} \mathrm{Ce}$ ratio as described above and was recalculated in the ${ }^{140} \mathrm{Ce}$ space (i.e. ${ }^{140} \mathrm{Ce}$ as a denominator). This yielded ${ }^{136} \mathrm{Ce} /{ }^{140} \mathrm{Ce}=0.00212,{ }^{138} \mathrm{Ce} /{ }^{140} \mathrm{Ce}=0.0248$ and ${ }^{142} \mathrm{Ce} /{ }^{140} \mathrm{Ce}=0.12588$.

For triple spike runs performed in metal form, the same procedure was used with metal Ce intensities except that no tailing and oxide corrections were performed (see below for details).

\section{Results and Discussion}

\subsection{Separation of Ce from the samples matrix}

High precision measurements of $\mathrm{Ce}$ isotopes by TIMS require the separation of $\mathrm{Ce}$ from the sample matrix in order to minimise isobaric interferences. Several methods have previously been reported to separate Ce from silicate matrices. The main problem with obtaining high precision Ce isotopes measurement, especially in metal mode (see below), is the complete removal of Ba during the chromatography procedure. The efficacy of our Ce separation technique was tested using synthetic multi-elemental solution and a certified basalt reference material (BHVO-2). Figure 2 shows welldefined and separated elution peaks during the chromatography procedure. Importantly, interfering elements such as $\mathrm{Ba}$ and $\mathrm{Nd}$ are separated from $\mathrm{Ce}$ in the first and second step of the column chemistry, respectively. After the three steps column procedure, the $\mathrm{Ba} / \mathrm{Ce}$ and $\mathrm{Nd} / \mathrm{Ce}$ ratios are decreased to 0.002 and 0.001 respectively. The total blank of our Ce separation procedure is about $0.5 \mathrm{ng}$, which is negligible $(<0.1 \%)$ compared to the amount of Ce processed through the columns ( 700 ng).

\subsection{Accuracy and reproducibility of radiogenic measurements}

Two Ce reference materials were analysed during the course of this study for their radiogenic $\mathrm{Ce}$ isotope composition. The results obtained in the different analytical setups are summarised in Table 4 and Figure 5. Wilbold $(2007)^{7}$ demonstrated that Ce isotope measurements in metal form were 
strongly affected by Ba interference most likely coming from the filaments. We therefore decided to measure radiogenic Ce isotope in oxide form only, testing several cup configurations. Using the multistatic cup configuration, the ${ }^{138} \mathrm{Ce} /{ }^{142} \mathrm{Ce}$ obtained for the $\mathrm{Ce}_{\text {AmEs }}$ reference material is $0.0225743 \pm$ 0.0000005 ( 2 s.d., $\mathrm{n}=5$ ). For the static cup configuration without ${ }^{140} \mathrm{Ce}^{16} \mathrm{O}$, the ${ }^{138} \mathrm{Ce} /{ }^{142} \mathrm{Ce}$ obtained for the $\mathrm{Ce}_{\mathrm{AMES}}$ and $\mathrm{Ce}_{\mathrm{LMV}}$ reference materials are $0.0225743 \pm 0.0000007$ ( 2 s.d., $\mathrm{n}=25$ ) and $0.0225705 \pm$ 0.0000006 ( 2 s.d., $\mathrm{n}=48$ ) respectively. Finally, for the static cup configuration with ${ }^{140} \mathrm{Ce}^{16} \mathrm{O}$, the ${ }^{138} \mathrm{Ce} /{ }^{142} \mathrm{Ce}$ obtained for the $\mathrm{Ce}_{\mathrm{AmES}}$ and $\mathrm{Ce}_{\text {LMv }}$ reference materials are $0.0225746 \pm 0.0000001$ (2 s.d., $\mathrm{n}=5)$ and $0.0225706 \pm 0.0000005$ ( 2 s.d., $\mathrm{n}=7$ ) respectively. The ${ }^{138} \mathrm{Ce} /{ }^{142} \mathrm{Ce}$ ratios obtained for both Ce reference materials in all cup configurations are always identical within uncertainty (Table 4). There is also a good agreement between our data and the literature values but our reproducibility is better than previously reported..$^{6,12,18-20}$ Contrary to earlier studies, the data presented here have not been normalised to a reference session which tends to improve the external reproducibility. In the cup configurations \#4, 5 and 6 , the ${ }^{140} \mathrm{Ce} /{ }^{142} \mathrm{Ce}$ ratios were also determined and we obtained for our reference materials ${ }^{140} \mathrm{Ce} /{ }^{142} \mathrm{Ce}$ AmES $=7.94416 \pm 0.00023$ ( 2 s.d., $\mathrm{n}=5$ ) and ${ }^{140} \mathrm{Ce} /{ }^{142} \mathrm{Ce}$ Lmv $=7.94397 \pm$ 0.00018 ( 2 s.d., $n=7$ ). There is about 100 ppm difference between our value and the value reported by Willig and Stracke $(2017)^{13}$. The difference between these values is possibly due to the use of two different mass spectrometers with variable faraday cups ages ${ }^{46}$ and/or due to the different cup configurations $\left({ }^{140} \mathrm{Ce}\right.$ measured in axial and $\left.\mathrm{L} 1 \mathrm{cups}\right)$. However, this small difference is negligible for the correction of the contribution of ${ }^{140} \mathrm{Ce}^{18} \mathrm{O}$ onto ${ }^{142} \mathrm{Ce}^{16} \mathrm{O}$ when ${ }^{140} \mathrm{Ce}^{16} \mathrm{O}$ is not measured. Two geological reference materials (BHVO-2 and BCR-2) were also analysed for their Ce radiogenic isotopic compositions. The ${ }^{138} \mathrm{Ce} /{ }^{142} \mathrm{Ce}$ ratios together with the ${ }^{140} \mathrm{Ce} /{ }^{142} \mathrm{Ce}$ ratios are given in Table 1 . For BHVO-2, the ${ }^{138} \mathrm{Ce} /{ }^{142} \mathrm{Ce}$ and ${ }^{140} \mathrm{Ce} /{ }^{142} \mathrm{Ce}$ ratios obtained are $0.0225650 \pm 0.0000004$ ( 2 s.d., $\mathrm{n}=2$ ) and $7.94389 \pm 0.00003$ ( 2 s.e., $\mathrm{n}=1$ ), respectively. For $\mathrm{BCR}-2$, the ${ }^{138} \mathrm{Ce} /{ }^{142} \mathrm{Ce}$ and ${ }^{140} \mathrm{Ce} /{ }^{142} \mathrm{Ce}$ ratios obtained are $0.0225670 \pm 0.0000005$ ( 2 s.d., $n=5$ ) and $7.94362 \pm 0.00003$ ( 2 s.e., $n=1$ ), respectively. The ${ }^{138} \mathrm{Ce} /{ }^{142} \mathrm{Ce}$ values presented in this study are in agreement with previous estimates of the ${ }^{138} \mathrm{Ce} /{ }^{142} \mathrm{Ce}$ ratios for these two geological reference materials. ${ }^{13,19,20}$ 

of those has advantages and inconveniences and we will now try to compare the results with previously published results and highlight the gain of the new technique. In terms of reproducibility, the ${ }^{138} \mathrm{Ce} /{ }^{142} \mathrm{Ce}$ ratio can be measured, using the static cup configuration, at about $25 \mathrm{ppm}$, which is comparable to the reproducibility obtained for the same reference material during dynamic measurements. However, the run duration is divided by 1.5 and the amount of Ce required also decreases to $700 \mathrm{ng}$. The main advantage of the method used in this study is the ability to reduce the counting time by $30 \%$ to obtain similar internal reproducibility. If the Ce quantity is the same, the signal intensity can be increased and then the internal precision will be better since the counting statistic is the main factor limiting the internal precision. We also performed Ce isotopic measurements with $250 \mathrm{ng}$ of $\mathrm{Ce}$ and we could run $\mathrm{CeO}$ at about $2.5 \mathrm{~V}(0.025 \mathrm{nA})$ of ${ }^{142} \mathrm{Ce}^{16} \mathrm{O}$. The reproducibility obtained is about $45 \mathrm{ppm}$, which is slightly higher than the optimised conditions but still acceptable for many applications. Compared to literature values, our reproducibility is similar or better than recently published Ce isotopes measurements (Table 1 ) $\cdot{ }^{13}$ The second advantage of the simultaneous measurement of $\mathrm{Ce}$ isotopes and the half masses tailing is that it does not require mass shift during the run. Finally, the main inconvenience of using our new cup configuration is the correction for $\mathrm{Ba}$ interference on the ${ }^{136} \mathrm{Ce}$ and ${ }^{138} \mathrm{Ce}$ isotopes. The static cup configuration uses the less abundant ${ }^{134} \mathrm{Ba}(\sim 2.4 \%)$ whereas the multi-static method used the slightly more abundant ${ }^{137} \mathrm{Ba}$ ( 11.2 \%). This reduces our ability to measure small amount of Ba by about 4 which could potentially be a problem. However, the chemical separation presented in this study is designed to effectively separate $\mathrm{Ba}$ from the Ce fraction to level well below detection limit. Furthermore, due to the high measurements.

\subsection{The utility of $10^{13}$ amplifiers}


In previous studies, the faraday cups were always coupled with $10^{11} \Omega$ amplifiers and this configuration allows the definition of the tailing from ${ }^{140} \mathrm{Ce}^{16} \mathrm{O}$ when routine beams of $10 \mathrm{~V}(0.1 \mathrm{nA})$ of ${ }^{142} \mathrm{Ce}^{16} \mathrm{O}$ were measured. One of the aims of this study is to develop a new method to measure $\mathrm{Ce}$ isotopes at high precision with smaller quantities. To this end, we used $10^{13} \Omega$ resistors on the tailing masses. The signal/noise on the $10^{13} \Omega$ resistors is supposed to be 10 times better than the typical $10^{11}$

$\Omega$ resistors. Thus the new amplifiers allow the measurements of small beams with better precision than typical $10^{11} \Omega$ amplifiers. In Figure 6, the intensities measured for the tailing masse 154.5 with two different resistors are shown. The signal measured $(0.35 \mathrm{fA})$ with $10^{13} \Omega$ resistor is less noisy by a factor of five compared to $10^{11} \Omega$ resistor which is comparable to the predicted improvement of ten. The standard deviation for a stable beam of $0.35 \mathrm{fA}$ improves from $0.35 \mathrm{fA}$ when using $10^{11} \Omega$ amplifier and 4 seconds integration time to $0.25 \mathrm{fA}\left(10^{11} \Omega\right.$ amplifier and $8 \mathrm{~s}$ integration time) and $0.05 \mathrm{fA}\left(10^{13}\right.$ $\Omega$ amplifier and $8 \mathrm{~s}$ integration time). For runs at high intensities $\left(0.1 \mathrm{nA}{ }^{142} \mathrm{Ce}^{16} \mathrm{O}\right)$, the tailing measured with $10^{11} \Omega$ resistors is precisely defined (Fig. 4). As expected, the tailing produced during a low intensity Ce isotope measurements $\left(0.03 \mathrm{nA}\right.$ on $\left.{ }^{142} \mathrm{Ce}{ }^{16} \mathrm{O}\right)$ is much smaller than at high intensity although its relative intensity compared to the measured Ce signals is the same (Fig. 4). Using $10^{13} \Omega$ resistors, we could define a good tailing where it was more difficult with typical $10^{11} \Omega$ resistors. This indicates that it is possible to produce high precision Ce isotopes measurements with lower signals than previously suggested and $250 \mathrm{ng} \mathrm{Ce}\left(\sim 0.03 \mathrm{nA}\right.$ of $\left.{ }^{142} \mathrm{Ce}^{16} \mathrm{O}\right)$ is enough to obtain a precise ${ }^{138} \mathrm{Ce} /{ }^{140} \mathrm{Ce}$ ratio. We also performed a few experiments with ${ }^{136} \mathrm{Ce}$ and ${ }^{138} \mathrm{Ce}$ signals with $10^{13} \Omega$ resistors using the multi-static cup configuration (\#1). The slow response time of these resistors means that after the jump, it was not possible for the signals to go back to the baseline values in a reasonable time. We therefore think that it is currently difficult to use $10^{13} \Omega$ resistors in dynamic measurements. The best cup configurations (\#4 and \#5, Table 1 ) for radiogenic Ce isotopic measurements are a combination of $10^{10}, 10^{11}, 10^{12}$ and $10^{13} \Omega$ resistors. If analysed, the main Ce peak $\left({ }^{140} \mathrm{Ce}{ }^{16} \mathrm{O}\right)$ is measured with a $10^{10}$ or $10^{11} \Omega$ resistor in high and low intensity runs, respectively. The second most abundant Ce mass $\left({ }^{142} \mathrm{Ce}^{16} \mathrm{O}\right)$ is always measured with $10^{11} \Omega$ resistor. The low intensities signals on 
masses ${ }^{136} \mathrm{Ce}^{16} \mathrm{O}$ and ${ }^{138} \mathrm{Ce}^{16} \mathrm{O}$ are measured using $10^{12} \Omega$ resistors. Finally, the tailing masses in cups $L 4, L 2, L 1$ and $H 1$ are measured with $10^{13} \Omega$ resistors. The best cup configuration used for the triple spike runs is a combination of $10^{11}$ and $10^{13} \Omega$ resistors. The Ce masses and the tailing are measured with $10^{11}$ and $10^{13} \Omega$ resistors, respectively.

The newly developed cup configuration allowed the determination of the tailing effect on masses

${ }^{136} \mathrm{Ce}$ and ${ }^{138} \mathrm{Ce}$. The lack of jump and the longer integration time of the static measurement mean that the tailing is more stable. The long-term tailing correction for the data presented in this study is 0.73 $\pm 0.13 \varepsilon$ which is slightly better than the reproducibility obtained per session using the multi-static cup configuration \#1 (from 0.14 to 0.51$).{ }^{42}$ The tailing effect during analysis at low intensity $\left(3 \mathrm{~V}{ }^{142} \mathrm{Ce}{ }^{16} \mathrm{O}\right.$ ) is similar ( $0.71 \pm 0.15 \varepsilon$ unit) in size. This indicates that the newly developed cup configuration allows a more reproducible determination of the tailing effect from ${ }^{140} \mathrm{Ce}^{16} \mathrm{O}$ onto masses ${ }^{136} \mathrm{Ce}^{16} \mathrm{O}$ and ${ }^{138} \mathrm{Ce}^{16} \mathrm{O}$.

\subsection{Spike calibrations and mass dependent Ce isotope measurements}

The triple spike was calibrated in oxide mode and the results are presented in Table 5 and Figure 7. Three spike mixtures were analysed and the $\delta^{142} \mathrm{Ce}$ values recovered by the triple spike technique are within uncertainty of $0 \%$ as expected but the overall average value is slightly positive with $\delta^{142} \mathrm{Ce}$ values ranging from -0.015 to $0.023 \%$. The best reproducibility is obtained by the spike/standard mixture ratio of 0.30 and is $\delta^{142} \mathrm{Ce}=0.023 \pm 0.052 \%$ ( 2 s.d., $\mathrm{n}=13$ ). However, there is no difference between the three spike-sample mixtures analysed in this study. The internal uncertainty ( 2 s.e.) of measurements of $\delta^{142} \mathrm{Ce}$ in the standard-spike mixture runs is usually better than $0.015 \%$. The results were deconvolved with and without tail correction. In this case, the tail correction does not change the deconvolved value suggesting that the increase in intensities due to spike addition is sufficient to make the contribution of tailing on masses 154 and 156 negligible. The large difference between our internal uncertainty and our external reproducibility is difficult to understand. One possibility is that 
this difference originates from the oxide correction applied to the raw data. Further tests are needed to understand this observation.

A standard-spike mixture was also analysed in metal mode. In this case, no tailing correction was performed because of the increase in signal intensities with the spike addition. The main difference with the oxide run is the presence of small amount of $\mathrm{Ba}$. The Ba interference correction is important during analysis in metal form. The cup configuration allows the measurement together with the Ce isotopes of ${ }^{137} \mathrm{Ba}$ that is slightly higher than ${ }^{134} \mathrm{Ba}$. The Ba signals are difficult to control during TIMS measurements and are unpredictable. Several factors seem to favour Ba emission. Among them are a rapid heating and a high ionisation current. However, when the Ba interference is well controlled, the reproducibility obtained on the standard-spike mixture is $\delta^{142} \mathrm{Ce}=-0.083 \pm 0.028 \%$, which is better than the reproducibility obtained in oxide mode and in the methods proposed in the literature..$^{22,25}$ This value is slightly lighter than the expected $\delta^{142} \mathrm{Ce}$ value of 0 . The main reason for this discrepancy is probably the fact that the correction procedure is different between metal and oxide analyses.

\subsection{Effects of isobaric interferences}

In most natural samples, $\mathrm{Ce}$ is present as a trace element and $\mathrm{Ba}$ and $\mathrm{Nd}$ can be present as a minor component ( $\mathrm{Ba} / \mathrm{Ce}$ and $\mathrm{Nd} / \mathrm{Ce}$ ratios up to 200 and 30, respectively). In some rare cases such as monazite, both $\mathrm{Ce}$ and $\mathrm{Nd}$ can be present at the percent level. The Ce separation is designed to remove the matrix elements and the main isobaric interference elements but it is nevertheless important to carefully consider the potential effects of isobaric interferences from Ba on ${ }^{136} \mathrm{Ce}$ and ${ }^{138} \mathrm{Ce}$ and $\mathrm{Nd}$ on ${ }^{142} \mathrm{Ce}$. In order to correct for isobaric interferences in both unspiked and spiked runs, two key assumptions are made. Firstly, the instrumental mass bias for $\mathrm{Ce}, \mathrm{Ba}$ and $\mathrm{Nd}$ is assumed to be the same for all elements involved. Secondly, the interfering elements are considered to have natural isotopic compositions because it is not possible to determine simultaneously the $\mathrm{Ce}$, Ba and $\mathrm{Nd}$ isotopic compositions. It is well documented that cation exchange chromatography can lead to large isotopic 
fractionation. The chemical separation is designed to remove the isobaric interference and the small quantities remaining in the Ce fraction is likely to be heavily fractionated.

In order to test the sensitivity of our interference corrections in the spike deconvolution procedure, we have performed some simple numerical calculations. A spiked Ce-LMV solution is "contaminated" with variable amounts of $\mathrm{Ba}, \mathrm{Nd}$ and $\mathrm{La}$, which have their isotopic compositions that differ from the "natural" composition by $-3 \%$ to $+3 \%$. These mixtures are then fractionated using the exponential mass fractionation law by the typical amount of TIMS Ce measurement. The resulting compositions are then put through our triple spike deconvolution procedure, which calculates the isotopic composition of the Ce-LMV reference material. These calculations are performed in metal form and the results are presented in Figure 8. The deconvolution procedure recovers a $\delta^{142} \mathrm{Ce}$ of 0 when the natural compositions are assumed for $\mathrm{Ba}, \mathrm{Nd}$ and La, as would be expected. However, it is important to note that the recovered $\delta^{142} \mathrm{Ce}$ values deviate from zero when non-natural values are assumed. For example, if the contaminant Ba has an isotopic composition that is fractionated from the natural composition by $1 \%$ and the ${ }^{137} \mathrm{Ba} /{ }^{142} \mathrm{Ce}=0.006$, then the recovered $\delta^{142} \mathrm{Ce}$ value is +0.1 \%o (Fig. 8). This non-negligible interference correction should be applied with care. The chemical separation allows a good separation between Ce and its isobaric interferences. Typical silicate samples analysed in this study, after column chemistry, have ${ }^{138} \mathrm{Ba} /{ }^{138} \mathrm{Ce},{ }^{143} \mathrm{Nd} /{ }^{142} \mathrm{Ce}$ and ${ }^{139} \mathrm{La} /{ }^{138} \mathrm{Ce}$ ratios of less than $0.004,0.0001$ and 0.002 respectively. The uncertainty introduced by the interference correction would be negligible even in the case of non-natural isotopic composition of the contaminants.

\section{Conclusions}

A method has been developed that allows effective separation of small quantities of $\mathrm{Ce}(\sim 700 \mathrm{ng})$ from silicate samples using a three-step column chemistry procedure. This chemical separation procedure allows the effective separation of $\mathrm{Ce}$ from $\mathrm{Nd}$ and $\mathrm{Ba}$, two isobaric interference elements. 
During the course of this study, several cup configurations were tested in order to measure radiogenic $\mathrm{Ce}$ isotopes at high precision. The newly developed static acquisition method allows the simultaneous measurement of the four $\mathrm{Ce}$ isotopes and their isobaric interferences $\left({ }^{134} \mathrm{Ba},{ }^{139} \mathrm{La}\right.$ and

${ }^{143} \mathrm{Nd}$ ) together with intercalated masses for tailing correction. The reproducibility obtained with two

Ce reference materials (Ce-LMV and Ce-AMES) is about $27 \mathrm{ppm}$ which is similar to previous TIMS methodologies. The main advantage of our new configuration is the reduced counting time necessary to obtain high precision data. This also indicates that high precision measurements can be performed with smaller amount of $\mathrm{Ce}(\sim 700 \mathrm{ng})$. The use of the $10^{13} \Omega$ resistors to measure the tailing masses allows the measurements of even smaller Ce quantities ( $250 \mathrm{ng}$ ) with a reproducibility of about 43 ppm. The new analytical technique allows a more stable determination of the tailing effect on masses ${ }^{136} \mathrm{Ce}$ and ${ }^{138} \mathrm{Ce}$.

A triple spike method has been developed to measure mass dependent Ce isotopic variations. To this end, uncertainty models were calculated on three commercially available Ce spikes and the best mixture is a triple spike containing ${ }^{136} \mathrm{Ce}-{ }^{138} \mathrm{Ce}-{ }^{140} \mathrm{Ce}$ isotopes. The spike/standard ratio of 0.33 produces the best spiking mixture in order to reduce the uncertainty magnification produced by adding spike to the natural samples. Two analytical methods were used to measure stable Ce isotopes on the TIMS and the runs in metal produce the best reproducibility. The main problem with $\mathrm{Ce}$ isotopes measurements in metal is the correction for Ba interferences on ${ }^{136} \mathrm{Ce}$ and ${ }^{138} \mathrm{Ce}$. However, the chemical separation described in this study allows an effective separation of Ba and Ce. We have also performed a number of calculations to characterise the sensitivity of our method to the interferences correction and the fact that we always assume natural compositions for the interfering elements. These calculations show that a small change in the isotopic composition will have a big impact on the recovered $\delta^{142} \mathrm{Ce}$ values. It is therefore fundamental to perfectly isolate Ce from the matrix and the isobaric interference elements in order to produce accurate and precise mass dependent stable Ce isotope measurements. 
References

1 H. Elderfield and M. J. Greaves, Nature, 1982, 296, 214-219.

2 A. D. Burnham and A. J. Berry, Geochim. Cosmochim. Acta, 2012, 95, 196-212.

3 D. Trail, E. B. Watson and N. D. Tailby, Nature, 2011, 480, 79-82.

4 D. J. Smythe and J. M. Brenan, Earth Planet. Sci. Lett., 2016, 453, 260-266.

5 D. J. Smythe and J. M. Brenan, Geochim. Cosmochim. Acta, 2015, 170, 173-187.

6 K.J.R. Rosman and P.D.P. Taylor, Pure Appl. Chem., 1998, 70, 217-236.

7 M. Willbold, J. Anal. At. Spectrom., 2007, 22, 1364-1372.

8 T. Tanaka and A. Masuda, Nature, 1982, 300, 515-518.

9 T. Tanaka, H. Shimizu, Y. Kawata and A. Masuda, Nature, 1987, 327, 113-117.

10 P. Dickin, Nature, 1987, 325, 337-338.

11 H. Shimizu, T. Tanaka and A. Masuda, Nature, 1984, 307, 251-252.

12 H. Shimizu, H. Sawatari, Y. Kawata, P. N. Dunkley and A. Masuda, Contrib. Mineral. Petrol., 1992, 110, 242-252.

13 M. Willig and A. Stracke, Chem. Geol., 2017, 476, 119-129.

14 C. Schnabel, C. Münker and E. Strub, J. Anal. At. Spectrom., 2017, 32, 2360-2370.

15 M. Tanimizu, Phys. Rev. C, 2000, 62, 017601-1-017601-4.

16 S.-G. Lee, Y. Asahara, T. Tanaka, N. H. Kim, K. H. Kim, K. Yi, A. Masuda, Y. S. Song, Chem. Geol., 2010, 276, 3-4, 360-373.

17 H. Shimizu, S. Nakai, S. Tasaki, A. Masuda, D. Bridgwater, A. P. Nutman and H. Baadsgaard, Earth Planet. Sci. Lett., 1988, 91, 159-169.

18 S. Nakai, H. Shimizu and A. Masuda, Nature, 1986, 320, 433-435.

19 R. Doucelance, N. Bellot, M. Boyet, T. Hammouda, C. Bosq, Earth Planet. Sci. Lett., 2014, 407, 175-186.

20 N. Bellot, M. Boyet, R. Doucelance, C. Pin, C. Chauvel and D. Auclair, Geochim. Cosmochim. Acta, 2015, 168, 261-279.

21 N. Bellot, M. Boyet, R. Doucelance, P. Bonnand, I. P. Savov, T. Plank, T. Elliott, Chem. Geol., 2018, https://doi.org/10.1016/j.chemgeo.2018.09.006

22 M. Tanimizu and T. Tanaka, Geochim. Cosmochim. Acta, 2002, 66, 4007-4014. 
23 A. Makishima and A. Masuda, Chem. Geol., 1994, 118, 1-8.

24 H. Amakawa, J. Ingri, A. Masuda and H. Shimizu, Earth Planet. Sci. Lett., 1991, 105, 554-565.

25 H. Shimizu, K. Tachikawa, A. Masuda and Y. Nozaki, Geochim. Cosmochim. Acta, 1994, 58, 323333.

26 H. Tazoe, H. Obata and T. Gamo, Geochem. Geophys. Geosyst., 2011, 12, 1-14.

27 R. Nakada, Y. Takahashi and M. Tanimizu, Geochim. Cosmochim. Acta, 2013, 103, 49-62.

28 R. Nakada, M. Tanaka, M. Tanimizu and Y. Takahashi, Geochim. Cosmochim. Acta, 2017, 218, 273290.

29 R. Nakada, Y. Takahashi and M. Tanimizu, Geochim. Cosmochim. Acta, 2016, 181, 89-100.

30 A. Laycock, B. Coles, K. Kreissig and M. Rehkämper, J. Anal. At. Spectrom., 2016, 31, 297-302

31 H. Tazoe, H. Obata and T. Gamo, J. Anal. At. Spectrom., 2007, 22, 616-622.

32 C.-F. Li, X.-C. Wang, Y.-L. Li, Z.-Y. Chu, J.-H. Guo and X.-H. Li, J. Anal. At. Spectrom., 2015, 30, 895902.

33 M. H. Dodson, J. Sci. Instrum., 1963, 40, 289-295.

34 F. Albarede and B. L. Beard, Rev. Mineral. Geochem., 2004, 55, 113-152.

35 J. F. Rudge, B. C. Reynolds and B. Bourdon, Chem. Geol., 2009, 265, 420-431.

36 M.-A. Millet, J. A. Baker and C. E. Payne, Chem. Geol., 2012, 304-305, 18-25.

37 B. L. A. Charlier, I. J. Parkinson, K. W. Burton, M. M. Grady, C. J. N. Wilson and E. G. C. Smith, Geochim. Persp. Let., 2017, 4, 35-40.

38 T. M. Conway, A. D. Rosenberg, J. F. Adkins and S. G. John, Analytica Chimica Acta, 2013, 793, 4452.

39 P. Bonnand, I. J. Parkinson, R. H. James, A.-M. Karjalainen and M. A. Fehr, J. Anal. At. Spectrom. 2011, 26, 528-535.

40 S. J. G. Galer, Chem. Geol., 1999, 157, 255-274.

41 K. R. Ludwig, U.S. Geol. Surv. Bull., 1986, 1622, 219-221.

42 N. Bellot, PhD thesis, Universite Blaise Pascal, 2016.

43 H. Shimizu, N. Umemoto, A. Masuda and P. W. U. Appel, Geochim. Cosmochim. Acta, 1990, 54, 1147-1154.

44 A. Makishima and E. Nakamura, chem. Geol., 1991, 94, 1-11. 
591

592

593

594

595

596

597

598

599

600

601

602

603

604

605

606

607

608

609

610

611

612

613

614

615

616

617

618

619

620

621

622

623

624

625

626

627

628

629

630

631

632

45 A. Makishima, H. Shimizu and A. Masuda, Mass Spectrosc., 1987, 35, 64-72.

46 M. Garçon, M. Boyet, R. W. Carlson, M. F. Horan, D. Auclair and T. D. Mock, Chem. Geol., 2018, 476, 493-514.

47 D. R. Lide, CRC Handbook of Chemistry and Physics, 1994, 75th ed. CRC Press.

\section{Conflicts of interest}

There are no conflicts to declare.

\section{Acknowledgments}

We would like to thank Matthias Willbold for providing his Ce reference material (Ce-AMES). PB would like to thank Alex Halliday for giving him the spikes. The reference material Ce-LMV is available upon request. We would like to thank Hauke Vollstaedt and Claudie Black for helpful discussions. We would like to thank Ryan Ickert for his thorough review that has improved the quality of this manuscript. This project has received funding from the European Research Council (ERC) under the European Union's Horizon 2020 research and innovation programme (Grant Agreement No 682778 - ISOREE). This is Laboratory of Excellence ClerVolc contribution number XXX. 


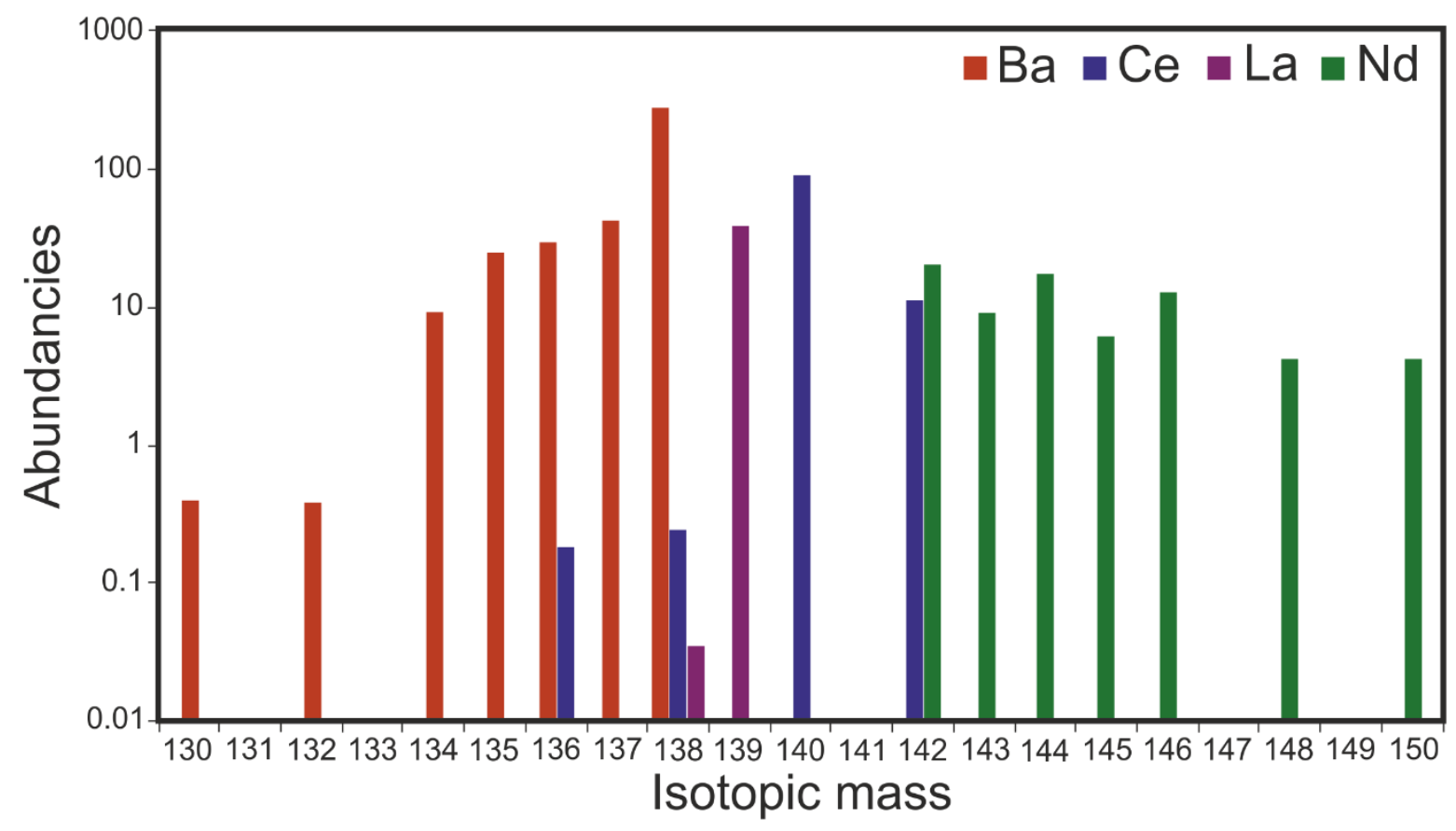

635 Figure 1: $\mathrm{Ce}, \mathrm{Nd}$, La and Ba isotopes abundances normalised to the primitive mantle elemental abundances. ${ }^{48}$ Note the logarithmic scale.

637

638

639

640

641

642

643

644

645

646

647

648

649

650

651

652

653

654

655

656

657 

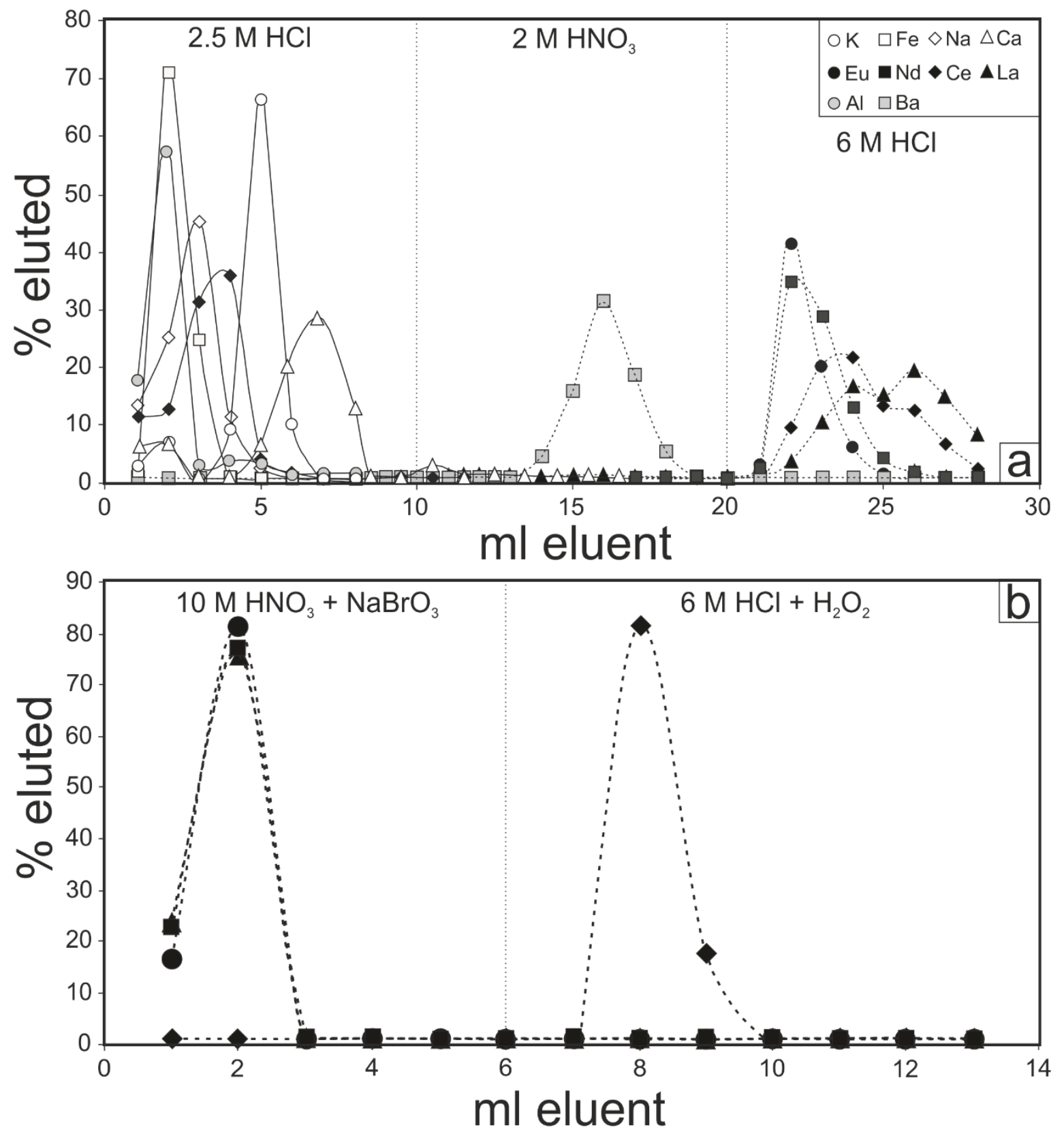

Figure 2: Elution curves for the first (a) and second (b) steps of the purification protocol used in this study. The first step was performed using AG50 X8, 200-400 mesh in $10 \mathrm{ml} \mathrm{Bio-Rad} \mathrm{columns.} \mathrm{The}$ second step was performed using using LnSpec Eichrom resin (50-100 $\mu \mathrm{m})$ in $2 \mathrm{ml}$ Bio-Rad columns. 

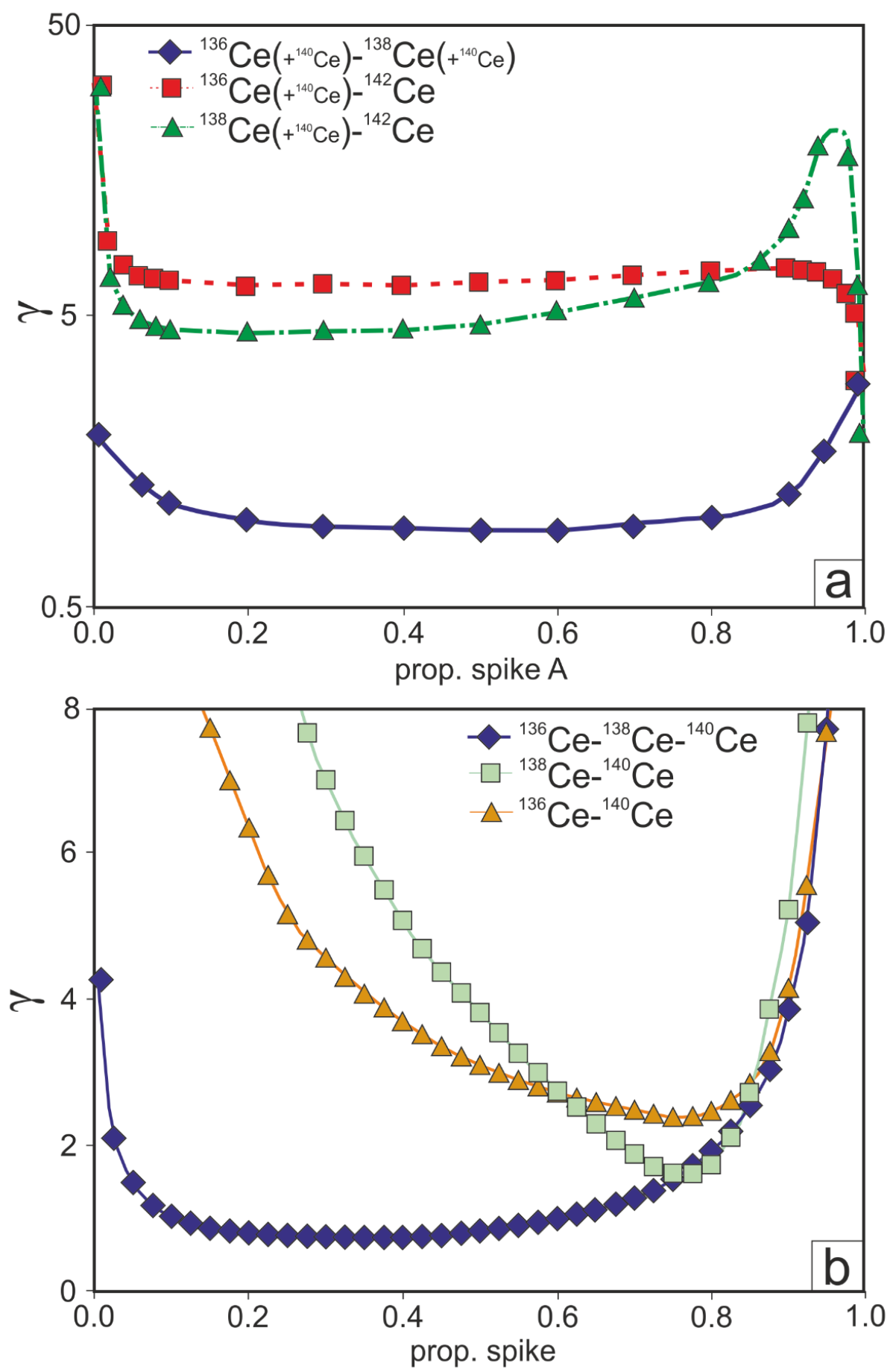

prop. spike

666 Figure 3: (a) Uncertainty magnification term ( $\nu$ ) for the deconvolved ${ }^{142} \mathrm{Ce} /{ }^{140} \mathrm{Ce}$ ratio as a function of

667 the proportion of spike $A$ in the spike mixtures. The spike $A$ is the first spike in the legend (for

668 example spike $\mathrm{A}$ is ${ }^{136} \mathrm{Ce}$ in the spike mixture ${ }^{136} \mathrm{Ce}-{ }^{142} \mathrm{Ce}$ ). (b) Uncertainty magnification term ( $\left.\gamma\right)$ for

669 three spikes (commercially available ${ }^{136} \mathrm{Ce}$ and ${ }^{138} \mathrm{Ce}$ spikes and a 50-50\% mixing on these two same

670 spikes) versus the proportion of spike in the standard spike mixtures (see text for details). A lower

671 gamma $(\gamma)$ value indicate a better spike mixture (a) or a better proportion of spike (b). 




672 673 Figure 4: Tailing measured in three analytical settings: green is the tailing with high intensities using
$67410^{11} \Omega$ resistor, blue is the tailing measured at low intensities using $10^{11} \Omega$ resistors and red is the 675 tailing measured at low intensities using $10^{13} \Omega$ resistors (See text for details). The measured 676 intensities ( $\mathrm{f} A$ ) on the tailing masses were divided by the intensities measured on ${ }^{142} \mathrm{Ce}^{16} \mathrm{O}$ for each 677 runs ( $\sim 0.03 \mathrm{nA}$ for green and red and $\sim 0.1 \mathrm{nA}$ for blue). All tailing masses were measured on the same 678 masses but for a better visibility of the tailing on the figure, the green and blue points are artificially 679 moved by +0.1 and -0.1 mass unit respectively.

680

681 

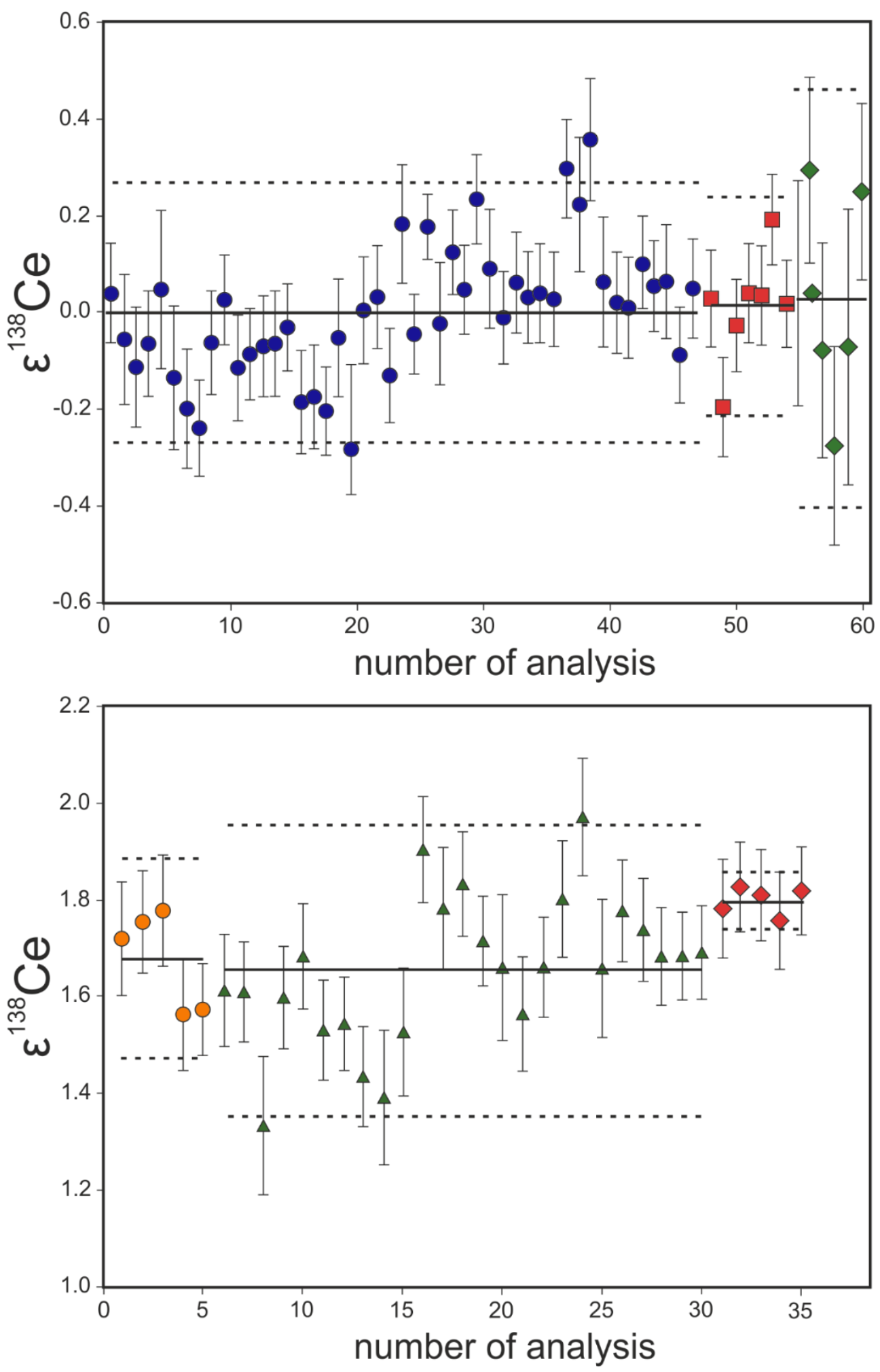

Figure 5: Long-term reproducibility of $\varepsilon^{138} \mathrm{Ce}$ for the LMV-Ce (a) and AMES-Ce (b) reference materials. (a) The blue circles, red squares and green diamonds data were obtained with cup configurations \#3, \#4 and \#5. The green diamonds were run at lower intensities. (b) The orange circles, green triangles and red diamonds data were obtained with cup configurations \#1, \#2 and \#4. The solid and dashed lines are the mean and 2 s.d. values for each configuration used in this study. 


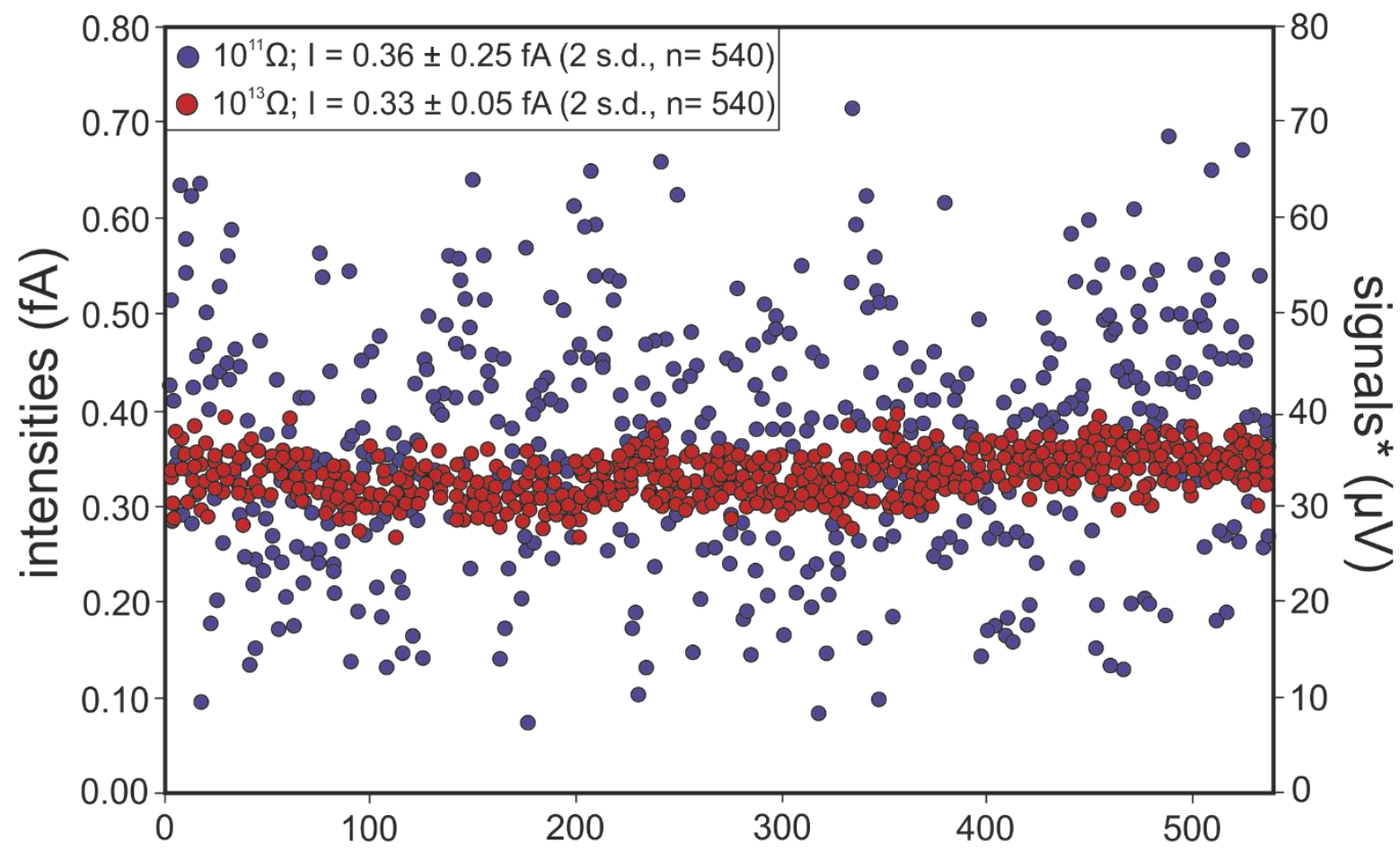

689

Figure 6: Typical signals measured at the tailing mass 154.5 with $10^{11} \Omega$ (blue) and $10^{13} \Omega$ (red) amplifiers during two measurements performed with $0.1 \mathrm{nA}$ on ${ }^{142} \mathrm{Ce}^{16} \mathrm{O}$. The signals expressed in voltages have been calculated relative to $10^{11}$ amplifiers.

692

693 




696 Figure 7: Mass dependent Ce isotopic compositions ( $\left.\delta^{142} \mathrm{Ce}\right)$ for the Ce-LMV reference material. The 697 squares, circles and triangles data points are three standard-spike mixtures run in oxides mode. The 698 orange diamonds are one standard-spike mixture run in metal mode (see text for details). The error 699 bars are internal uncertainties for each run. The solid and dashed lines are the mean and 2 s.d. 700 values for the four standard-spike mixtures, respectively. 

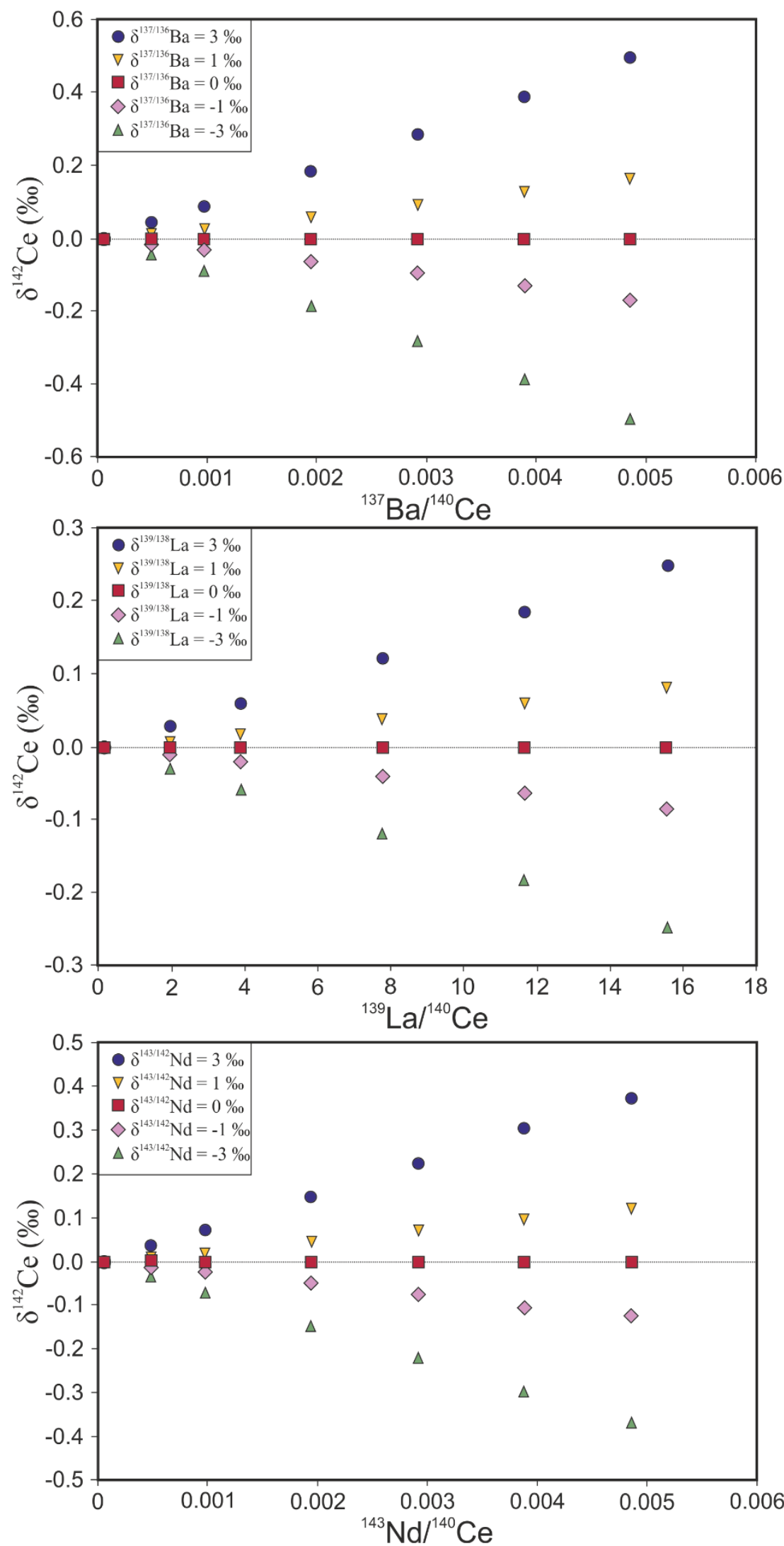

Figure 8: Effects of "non-natural" isobaric interferences from (a) Barium, (b) Lanthanum and (c)

704 Neodymium on $\delta^{142} \mathrm{Ce}$ as a function of the element/Ce ratio. The changing isotopic compositions for 705 the interfering elements are shown by the different symbols. 
Table 1: Cup configurations used on the Thermo-Scientific Triton plus TIMS at the Laboratoire Magmas et Volcans during the course of this study. The main isotope masses are in bold; the interference masses are in italic. ${ }^{134} \mathrm{Ba}^{16} \mathrm{O}$ is also ${ }^{150} \mathrm{Sm}$ and ${ }^{150} \mathrm{Nd} .{ }^{142} \mathrm{Ce}^{18} \mathrm{O}$ is also ${ }^{143} \mathrm{Nd}^{16} \mathrm{O}$.

\begin{tabular}{|c|c|c|c|c|c|c|c|c|c|c|c|c|}
\hline \multirow[b]{2}{*}{ run type } & \multirow[b]{2}{*}{ config \# } & \multicolumn{11}{|c|}{ Collectors } \\
\hline & & lines & L4 & L3 & $\mathrm{L} 2$ & $\mathrm{~L} 1$ & $\mathrm{C}$ & $\mathrm{H} 1$ & $\mathrm{H} 2$ & $\mathrm{H3}$ & $\mathrm{H} 4$ & integration time (s) \\
\hline \multirow[t]{3}{*}{ unspiked } & 1 & 1 & ${ }^{134} \mathrm{Ba}^{16} \mathrm{O}$ & ${ }^{136} \mathrm{Ce}^{16} \mathrm{O}$ & ${ }^{136} \mathrm{Ce}^{17} \mathrm{O}$ & ${ }^{138} \mathrm{Ce}^{16} \mathrm{O}$ & ${ }^{139} \mathrm{La}^{16} \mathrm{O}$ & ${ }^{142} \mathrm{Ce}^{16} \mathrm{O}$ & ${ }^{142} \mathrm{Ce}^{17} \mathrm{O}$ & ${ }^{142} \mathrm{Ce}^{18} \mathrm{O}$ & & 8.39 \\
\hline & & 2 & 150 & 152 & 153 & 154 & 155 & 158 & 159 & 160 & & 4.19 \\
\hline & & ampli $(\Omega)$ & $10^{11}$ & $10^{11}$ & $10^{11}$ & $10^{11}$ & $10^{11}$ & $10^{11}$ & $10^{11}$ & $10^{11}$ & & \\
\hline \multirow[t]{2}{*}{ unspiked } & 2 & 1 & ${ }^{134} \mathrm{Ba}^{16} \mathrm{O}$ & ${ }^{136} \mathrm{Ce}^{16} \mathrm{O}$ & 152.6 & 153.4 & ${ }^{138} \mathrm{Ce}^{16} \mathrm{O}$ & 154.6 & ${ }^{140} \mathrm{Ce}^{17} \mathrm{O}$ & ${ }^{142} \mathrm{Ce}^{16} \mathrm{O}$ & ${ }^{142} \mathrm{Ce}^{18} \mathrm{O}$ & 8.39 \\
\hline & & ampli $(\Omega)$ & $10^{11}$ & $10^{12}$ & $10^{11}$ & $10^{11}$ & $10^{12}$ & $10^{11}$ & $10^{11}$ & $10^{11}$ & $10^{11}$ & \\
\hline \multirow[t]{2}{*}{ unspiked } & 3 & 1 & ${ }^{134} \mathrm{Ba}^{16} \mathrm{O}$ & ${ }^{136} \mathrm{Ce}^{16} \mathrm{O}$ & 152.6 & 153.4 & ${ }^{138} \mathrm{Ce}^{16} \mathrm{O}$ & 154.6 & ${ }^{140} \mathrm{Ce}^{17} \mathrm{O}$ & ${ }^{142} \mathrm{Ce}^{16} \mathrm{O}$ & ${ }^{142} \mathrm{Ce}^{18} \mathrm{O}$ & 8.39 \\
\hline & & ampli $(\Omega)$ & $10^{13}$ & $10^{12}$ & $10^{13}$ & $10^{13}$ & $10^{12}$ & $10^{13}$ & $10^{11}$ & $10^{11}$ & $10^{11}$ & \\
\hline \multirow[t]{2}{*}{ unspiked } & 4 & 1 & ${ }^{134} \mathrm{Ba}^{16} \mathrm{O}$ & ${ }^{136} \mathrm{Ce}^{16} \mathrm{O}$ & 152.6 & 153.4 & ${ }^{138} \mathrm{Ce}^{16} \mathrm{O}$ & 154.6 & ${ }^{140} \mathrm{Ce}^{16} \mathrm{O}$ & ${ }^{142} \mathrm{Ce}^{16} \mathrm{O}$ & ${ }^{142} \mathrm{Ce}^{18} \mathrm{O}$ & 8.39 \\
\hline & & ampli $(\Omega)$ & $10^{13}$ & $10^{12}$ & $10^{13}$ & $10^{13}$ & $10^{12}$ & $10^{13}$ & $10^{\wedge} 10$ & $10^{11}$ & $10^{11}$ & \\
\hline \multirow[t]{2}{*}{ unspiked } & 5 & 1 & ${ }^{134} \mathrm{Ba}^{16} \mathrm{O}$ & ${ }^{136} \mathrm{Ce}^{16} \mathrm{O}$ & 152.6 & 153.4 & ${ }^{138} \mathrm{Ce}^{16} \mathrm{O}$ & 154.6 & ${ }^{140} \mathrm{Ce}^{16} \mathrm{O}$ & ${ }^{142} \mathrm{Ce}^{16} \mathrm{O}$ & ${ }^{142} \mathrm{Ce}^{18} \mathrm{O}$ & 8.39 \\
\hline & & ampli $(\Omega)$ & $10^{13}$ & $10^{12}$ & $10^{13}$ & $10^{13}$ & $10^{12}$ & $10^{13}$ & $10^{11}$ & $10^{11}$ & $10^{11}$ & \\
\hline \multirow[t]{2}{*}{ unspiked } & 6 & 1 & ${ }^{134} \mathrm{Ba}^{16} \mathrm{O}$ & ${ }^{136} \mathrm{Ce}^{16} \mathrm{O}$ & 152.6 & 153.4 & ${ }^{138} \mathrm{Ce}^{16} \mathrm{O}$ & 154.6 & ${ }^{140} \mathrm{Ce}^{16} \mathrm{O}$ & ${ }^{142} \mathrm{Ce}^{16} \mathrm{O}$ & ${ }^{142} \mathrm{Ce}^{18} \mathrm{O}$ & 8.39 \\
\hline & & ampli $(\Omega)$ & $10^{11}$ & $10^{11}$ & $10^{11}$ & $10^{11}$ & $10^{11}$ & $10^{11}$ & $10^{11}$ & $10^{11}$ & $10^{12}$ & \\
\hline \multirow[t]{2}{*}{ spiked } & 7 & 1 & ${ }^{134} \mathrm{Ba}^{16} \mathrm{O}$ & ${ }^{136} \mathrm{Ce}^{16} \mathrm{O}$ & 152.6 & 153.4 & ${ }^{138} \mathrm{Ce}^{16} \mathrm{O}$ & 154.6 & ${ }^{140} \mathrm{Ce}^{16} \mathrm{O}$ & ${ }^{142} \mathrm{Ce}^{16} \mathrm{O}$ & ${ }^{142} \mathrm{Ce}^{18} \mathrm{O}$ & 8.39 \\
\hline & & ampli $(\Omega)$ & $10^{13}$ & $10^{11}$ & $10^{13}$ & $10^{13}$ & $10^{11}$ & $10^{13}$ & $10^{11}$ & $10^{11}$ & $10^{\wedge} 12$ & \\
\hline \multirow[t]{2}{*}{ spiked } & 8 & 1 & & ${ }^{134} \mathrm{Ba}$ & ${ }^{136} \mathrm{Ce}$ & ${ }^{137} \mathrm{Ba}$ & ${ }^{138} \mathrm{Ce}$ & ${ }^{139} \mathrm{La}$ & ${ }^{140} \mathrm{Ce}$ & ${ }^{142} \mathrm{Ce}$ & ${ }^{143} \mathrm{Nd}$ & 8.39 \\
\hline & & ampli $(\Omega)$ & $10^{13}$ & $10^{11}$ & $10^{11}$ & $10^{11}$ & $10^{11}$ & $10^{11}$ & $10^{11}$ & $10^{11}$ & $10^{11}$ & \\
\hline
\end{tabular}


714

715

716 
Table 2: spikes isotopic compositions used in the theoretical calculations presented in Figure 3. See

718 text for details.

\begin{tabular}{cccr}
\hline spike & ${ }^{136} \mathrm{Ce}$ & ${ }^{138} \mathrm{Ce}$ & ${ }^{142} \mathrm{Ce}$ \\
\hline${ }^{136} \mathrm{Ce} /{ }^{140} \mathrm{Ce}$ & 0.001 & 0.809 & 0.021 \\
${ }^{138} \mathrm{Ce} /{ }^{140} \mathrm{Ce}$ & 0.745 & 0.015 & 0.021 \\
${ }^{142} \mathrm{Ce} /{ }^{140} \mathrm{Ce}$ & 0.046 & 0.080 & 20.234 \\
\hline
\end{tabular}

719

720

721

722

723

724

725

Table 3: Ce isotopic composition of the triple spike calibrated in this study.

\begin{tabular}{lcccccc} 
& ${ }^{136} \mathrm{Ce} /{ }^{140} \mathrm{Ce}$ & 2 s.d. & ${ }^{138} \mathrm{Ce} /{ }^{140} \mathrm{Ce}$ & 2 s.d. & ${ }^{142} \mathrm{Ce} /{ }^{140} \mathrm{Ce}$ & 2 s.d. \\
\hline LMV-Ce $(\mathrm{n}=48)$ & 0.00212484 & 0.00000008 & 0.0028412 & 0.0000001 & 0.125879 & 0.000005 \\
Triple spike $(\mathrm{n}=21)$ & 0.38706 & 0.00003 & 0.39570 & 0.00003 & 0.062070 & 0.000005 \\
\hline
\end{tabular}

726

727

728

729

730

731

732

733

734

735

736

737 
Table 4: Results for the radiogenic Ce isotopic composition of two solution reference materials (Ce-LMV and Ce-AMES) and two rock reference materials together with data from the literature. *the uncertainties are 2 standard errors.

\begin{tabular}{|c|c|c|c|c|c|c|c|c|c|c|c|c|}
\hline sample name & config \# & ${ }^{142} \mathrm{Ce}^{16} \mathrm{O}(\mathrm{V})$ & ${ }^{138} \mathrm{Ce} /{ }^{142} \mathrm{Ce}$ & 2 s.d. & ${ }^{138} \mathrm{Ce} /{ }^{136} \mathrm{Ce}$ & 2 s.d. & $\varepsilon^{138} \mathrm{Ce}_{\text {LMV }}$ & 2 s.d. & ${ }^{140} \mathrm{Ce} /{ }^{142} \mathrm{Ce}$ & 2 s.d. & $\mathrm{n}$ & ref \\
\hline LMV Ce & 3 & 9.9 & 0.02257053 & 0.00000061 & 1.337116 & 0.000036 & 0.00 & 0.27 & $\mathrm{~N} / \mathrm{A}$ & $\mathrm{N} / \mathrm{A}$ & 48 & This study \\
\hline LMV Ce & 4 & 9.6 & 0.02257056 & 0.00000051 & 1.337118 & 0.000030 & 0.01 & 0.23 & 7.94397 & 0.00014 & 7 & This study \\
\hline LMV Ce & 5 & 2.4 & 0.02257059 & 0.00000098 & 1.337120 & 0.000058 & 0.03 & 0.43 & 7.94417 & 0.00025 & 6 & This study \\
\hline LMV-Ce & 6 & 2.77 & 0.02257062 & 0.00000097 & 1.337122 & 0.000057 & 0.04 & 0.43 & 7.94403 & 0.00018 & 10 & This study \\
\hline AMES-Ce & 1 & 10.1 & 0.02257431 & 0.00000046 & 1.337341 & 0.000027 & 1.68 & 0.20 & $\mathrm{~N} / \mathrm{A}$ & $\mathrm{N} / \mathrm{A}$ & 5 & This study \\
\hline AMES-Ce & 2 & 9.55 & 0.02257426 & 0.00000068 & 1.337338 & 0.000040 & 1.66 & 0.30 & $\mathrm{~N} / \mathrm{A}$ & N/A & 25 & This study \\
\hline AMES-Ce & 4 & 10 & 0.02257458 & 0.00000013 & 1.337357 & 0.000008 & 1.80 & 0.06 & 7.94416 & 0.00023 & 5 & This study \\
\hline AMES-Ce & & & 0.02257497 & 0.00000050 & 1.337380 & 0.000030 & 1.97 & 0.22 & $\mathrm{~N} / \mathrm{A}$ & $N / A$ & 35 & Willbold 2007 \\
\hline AMES-Ce & & & 0.02257468 & 0.00000100 & 1.337363 & 0.000059 & 1.84 & 0.44 & $\mathrm{~N} / \mathrm{A}$ & N/A & 53 & Doucelance et al. 2014 \\
\hline AMES-Ce & & & 0.02257320 & 0.00000180 & 1.337275 & 0.000107 & 1.18 & 0.80 & N/A & N/A & 89 & Bellot et al. 2015 \\
\hline AMES-Ce & & & 0.02257474 & 0.00000048 & 1.337366 & 0.000028 & 1.87 & 0.21 & 7.94333 & 0.00031 & 9 & Willig and Stracke 2017 \\
\hline BCR-2 & 3 & 10.7 & 0.02256689 & 0.00000055 & 1.336901 & 0.000033 & -1.61 & 0.24 & $\mathrm{~N} / \mathrm{A}$ & N/A & 5 & This study \\
\hline BCR-2* & 4 & 11.2 & 0.02256696 & 0.00000020 & 1.336905 & 0.000012 & -1.58 & 0.09 & 7.943620 & 0.000025 & 1 & This study \\
\hline BCR-2 & & & 0.02256678 & 0.00000066 & 1.336894 & 0.000039 & -1.66 & 0.29 & $\mathrm{~N} / \mathrm{A}$ & $\mathrm{N} / \mathrm{A}$ & 3 & Doucelance et al. 2014 \\
\hline BCR-2 & & & 0.02256620 & 0.00000070 & 1.336860 & 0.000041 & -1.92 & 0.31 & N/A & $\mathrm{N} / \mathrm{A}$ & 4 & Bellot et al. 2015 \\
\hline BCR-2 & & & 0.02256719 & 0.00000063 & 1.336919 & 0.000037 & -1.48 & 0.28 & N/A & N/A & 20 & Willig and Stracke 2017 \\
\hline BHVO-2 & 3 & 8.7 & 0.02256489 & 0.00000047 & 1.336782 & 0.000028 & -2.50 & 0.21 & $\mathrm{~N} / \mathrm{A}$ & N/A & 2 & This study \\
\hline BHVO-2* & 4 & 10 & 0.02256499 & 0.00000024 & 1.336788 & 0.000014 & -2.45 & 0.11 & 7.943886 & 0.000032 & 1 & This study \\
\hline BHVO-2 & & & 0.02256550 & 0.00000154 & 1.336819 & 0.000091 & -2.23 & 0.68 & $\mathrm{~N} / \mathrm{A}$ & $\mathrm{N} / \mathrm{A}$ & 8 & Doucelance et al. 2014 \\
\hline BHVO-2 & & & 0.02256460 & 0.00000170 & 1.336765 & 0.000101 & -2.63 & 0.75 & N/A & N/A & 6 & Bellot et al. 2015 \\
\hline BHVO-2 & & & 0.02256482 & 0.00000059 & 1.336778 & 0.000035 & -2.53 & 0.26 & $\mathrm{~N} / \mathrm{A}$ & $\mathrm{N} / \mathrm{A}$ & 24 & Willig and Stracke 2017 \\
\hline
\end{tabular}


743 Table 5: Results for triple spike runs performed using the Ce-LMV reference material.

744

\begin{tabular}{|c|c|c|c|c|c|c|}
\hline sample name & run type & cup config. & spike/std & $\delta^{142}$ Ce & 2 s.d. & $\mathrm{n}$ \\
\hline LMV-Ce & oxide & 5 & 0.20 & 0.008 & 0.099 & 4 \\
\hline LMV-Ce & oxide & 5 & 0.33 & 0.023 & 0.052 & 13 \\
\hline LMV-Ce & oxide & 5 & 0.50 & -0.015 & 0.077 & 5 \\
\hline LMV-Ce & metal & 6 & 0.33 & -0.083 & 0.028 & 4 \\
\hline
\end{tabular}

